\title{
OPTIMAL REPLACEMENT, RETROFIT, AND MANAGEMENT OF A FLEET OF ASSETS UNDER REGULATIONS OF AN EMISSIONS TRADING SYSTEM
}

\author{
by
}

Amir Rajabian, B.Sc., Iran 2017

\author{
A thesis \\ presented to Ryerson University \\ in partial fulfillment of the \\ requirements for the degree of \\ Master of Applied Science \\ in the program of \\ Industrial Engineering
}

Toronto, Ontario, Canada, 2019

(C) Amir Rajabian, 2019 


\section{AUTHOR'S DECLARATION FOR ELECTRONIC SUBMISSION OF A THESIS}

I hereby declare that I am the sole author of this thesis. This is a true copy of the thesis, including any required final revisions, as accepted by my examiners.

I authorize Ryerson University to lend this thesis to other institutions or individuals for the purpose of scholarly research.

I further authorize Ryerson University to reproduce this thesis by photocopying or by other means, in total or in part, at the request of other institutions or individuals for the purpose of scholarly research.

I understand that my thesis may be made electronically available to the public. 
OPTIMAL REPLACEMENT, RETROFIT, AND MANAGEMENT OF A FLEET OF ASSETS

\title{
UNDER REGULATIONS OF AN EMISSIONS TRADING SYSTEM
}

Master of Applied Science, 2019

\author{
Amir Rajabian \\ Industrial Engineering \\ Ryerson University
}

\begin{abstract}
This thesis presents the development of a model for parallel replacement and improvement for a fleet of assets to minimize both the economic costs and greenhouse gas (GHG) emissions where the emissions are limited by cap-and-trade. The firm which owns the assets has the options of using the assets, putting them in inventory, improving them, or salvaging them. Different technological types and their performances have been considered for assets. The firm has the option of purchasing new assets from varying technologies and/or improving its existing assets to a higher-performance type. Moreover, the model considers the possibility of both banking the emission allowances and trading them in the market. The model was later used with data of a fleet of excavators in Ontario, Canada. The use of this model could help emitter firms to simultaneously manage the emissions and costs of their fleet of assets in a jurisdiction regulated by cap-and-trade.
\end{abstract}




\section{ACKNOWLEDGEMENTS}

I would like to thank my parents for their unqualified support and dedicating years of their life to provide for me, especially my Father, a man who always believed in me, inspired me, guided me, and led me in the most challenging times of my life, and a man who never preferred his own will over his family. I dedicate this thesis to their love.

I thank my supervisor, Dr. Sharareh Taghoipour, for trusting me, giving me this opportunity to pursue my dreams through this master's program. I thank her for being patient, helpful, supportive, and understanding. I dedicate this thesis to her willingness to give this precious opportunity to me.

I would like to thank my dear friend, Mr. Markus W. Jesswein, as he made the hardships of starting a new life and being far away from family and friends while facing challenges of graduate life, much easier by his valuable company and support. I dedicate this thesis to his sincere friendship.

I thank Mr. Christopher Brierly, a wonderful and dedicated teacher, and a great mentor. I thank him for all the things I learned from him and dedicate this thesis to his tireless efforts to help international students achieve their goals.

Lastly, I would like to acknowledge the Natural Sciences and Engineering Research Council (NSERC) for continuing to fund quality research generally, and for funding my research dreams, specifically. 


\section{PREFACE}

While Chapter 1 is an introduction to the work, Chapters 2 to 5 of this thesis draw heavily from the following journal paper submitted during my master's studies:

A. Rajabian, S. Taghipour, "Optimal replacement, retrofit, and management of a fleet of assets

under regulations of an emissions trading system", International Journal of Production Economics. Submitted in March 2019. 


\section{TABLE OF CONTENTS}

AUTHOR'S DECLARATION FOR ELECTRONIC SUBMISSION OF A THESIS ...................II

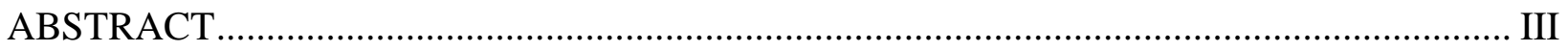

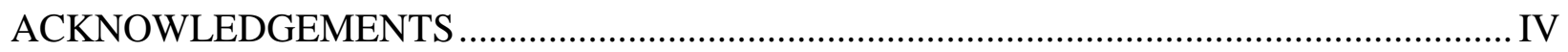

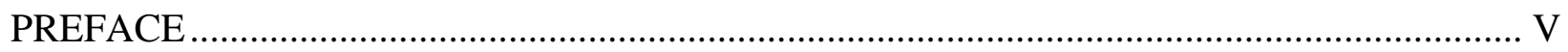

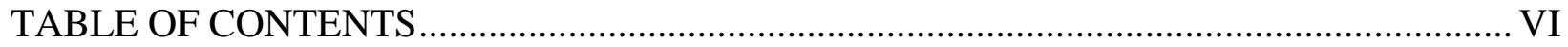

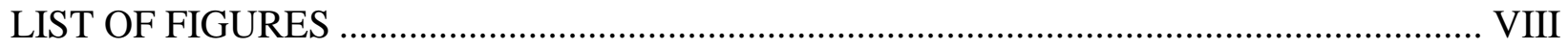

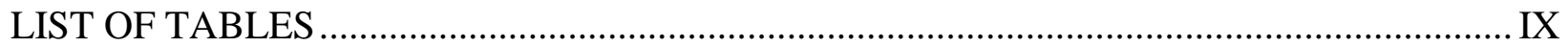

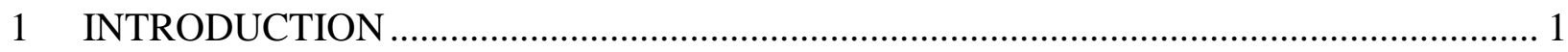

1.1 RESEARCH BACKGROUND ........................................................................ 1

1.2 CARBON PRICING AND EMISSIONS TRADING ............................................ 3

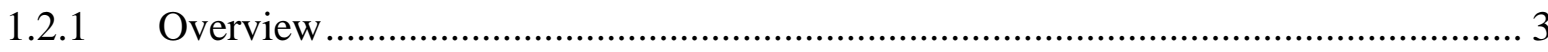

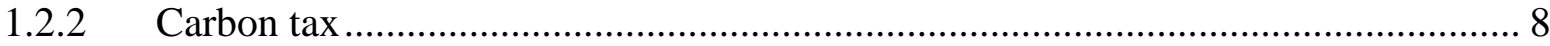

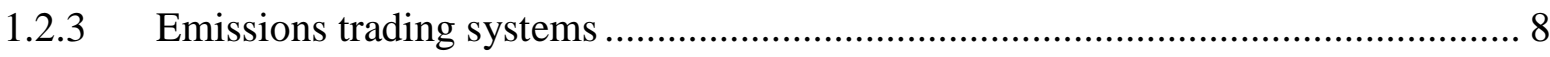

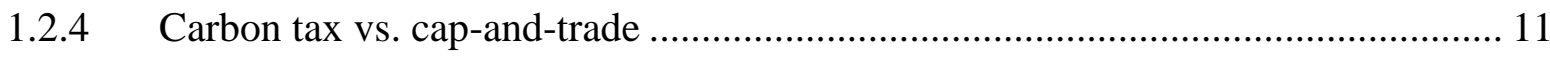

1.3 PARALLEL ASSET MANAGEMENT ........................................................... 12

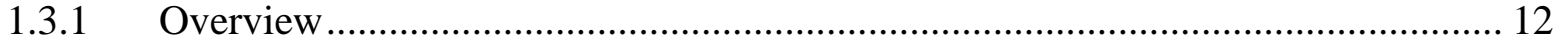

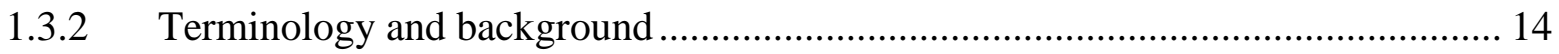

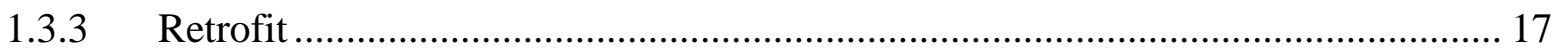

1.4 RESEARCH MOTIVATION AND SCOPE ........................................................ 18

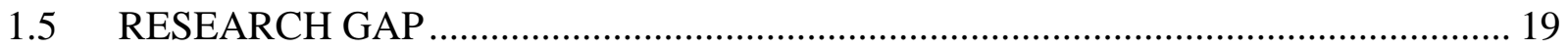




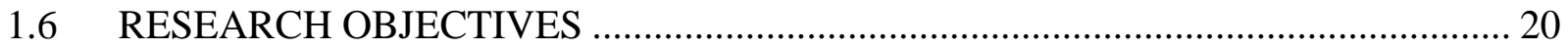

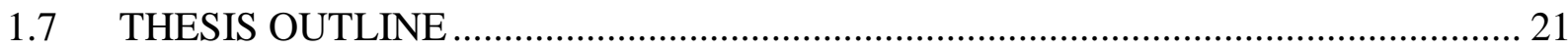

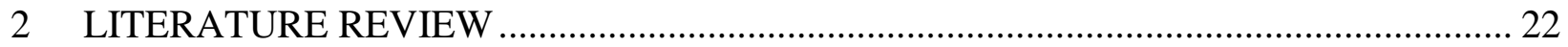

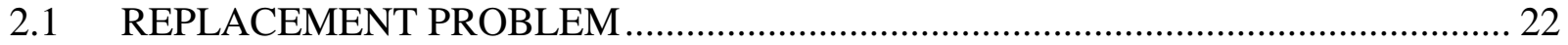

2.2 PAPERS CONSIDERING ECONOMIC FACTORS ONLY ..................................... 23

2.3 PAPERS INCLUDING ENVIRONMENTAL AND ECONOMIC FACTORS ........... 25

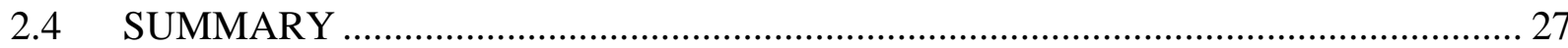

3 PROBLEM DESCRIPTION AND THE MODEL ....................................................... 28

4 CASE STUDY, RESULTS, AND SENSITIVITY ANALYSIS ................................... 40

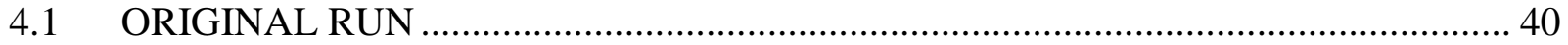

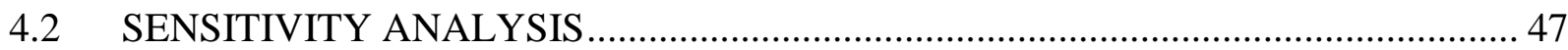

5 CONCLUSION AND FUTURE RECOMMENDATIONS ............................................ 53

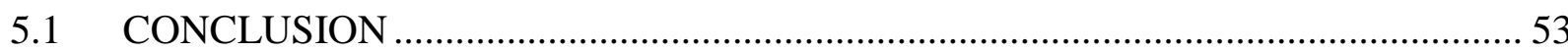

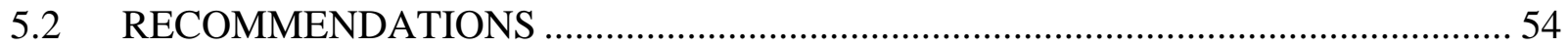

5.3 LIMITATIONS AND FUTURE WORK.......................................................... 55

APPENDIX: CPLEX MIXED INTEGER PROGRAM SOURCE CODE ............................... 56

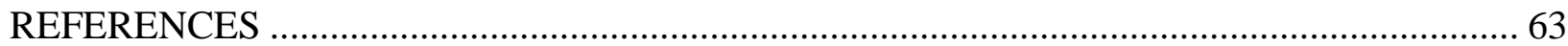




\section{LIST OF FIGURES}

Figure 1.1 Nanticoke Generating Station, the largest coal-fired power plant in North America which turned into a solar plant and started working in April 2019 ("Former coal-fired power

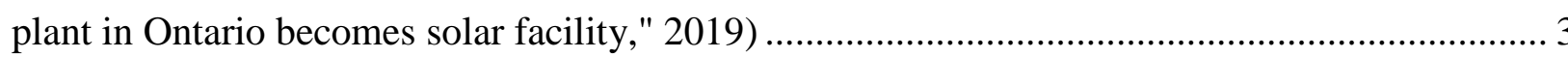

Figure 1.2 GHG emissions by sector since 1990 (Canadian Environmental Sustainability

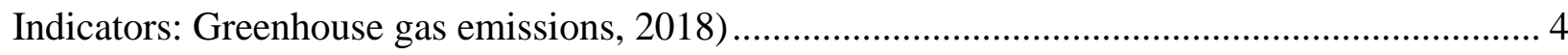

Figure 1.3 Overview of carbon pricing strategies around the world (Kossoy, 2015)................. 5

Figure 1.4 Percent of the global GHG emissions covered by carbon pricing schemes (Kossoy, 2015)

Figure 1.5 Emissions trading system (A Brief Look At The Quebec Cap-And-Trade-System For Emission Allowances, 2018) 10

Figure 1.6 cap on GHG emissions set by the Government of Quebec (A Brief Look At The Quebec Cap-And-Trade-System For Emission Allowances, 2018)

Figure 1.7 A manufacturing machine, an excavator, and a building. All examples of assets.

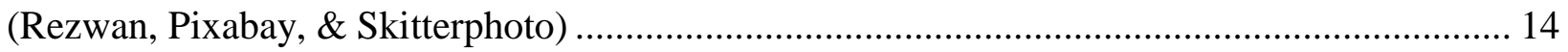

Figure 1.8 A fleet of buses used in urban transportation. (Imre) ......................................... 16

Figure 1.9 A silicone pump, adding a sensor to stop the flow once the pump runs out of silicone is an example of how retrofit results in waste reduction ("Dow Corning Silicone Pumps," 2019)

Figure 3.1 The options ahead of an asset at the beginning of each year 29 


\section{LIST OF TABLES}

Table 3.1 Definition of indices, decision variables, and parameters. ................................... 32

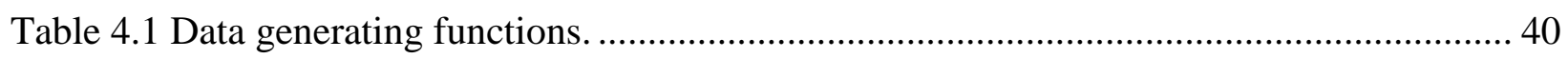

Table 4.2 Assets owned by the firm in the first year. ................................................... 41

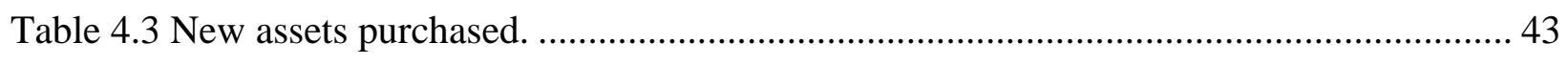

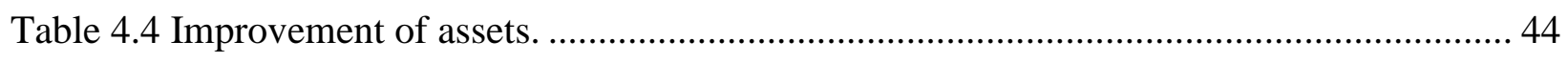

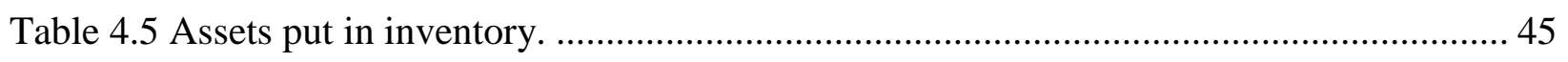

Table 4.6 The new assets purchased when the base cost of the improvement is cut in half. ....... 48

Table 4.7 The assets improved when the base cost of the improvement is cut in half............... 49

Table 4.8 The new assets purchased with a $2.5 \%$ increase in the price gap between technological

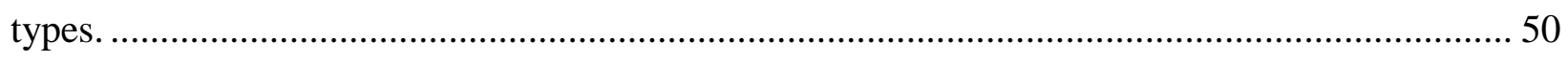

Table 4.9 The assets purchased with $2.5 \%$ increase in price gap between technological types ... 51

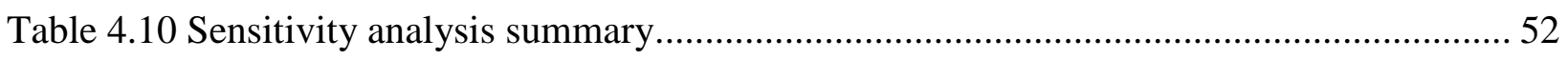




\section{INTRODUCTION}

\subsection{RESEARCH BACKGROUND}

Emissions trading or cap-and-trade systems are relatively new and are still developing all around the world. In Canada, Cap-and-trade systems have been established and used in Quebec, and previously Ontario, as a mean to control and limit the carbon footprint of these provinces and help the environment. The deployment of such a new system, similar to any change in policies, could raise concerns among manufacturers as to how they could manage their businesses effectively within the new platform.

Research and discussions concerning asset management and the replacement problem are considerably older than emissions trading systems. As cap-and-trade policies could change many factors of the decision, new models need to be developed to deem these changes. In this chapter, the background of this research and why it is important and needed in the industry will be discussed step by step and the gap in the research will be examined.

The first step to explain the importance of this work is to introduce the concerns over climate change and how that is related to physical asset management. In recent years, the issue of global climate change has been on the spotlight and individuals and corporations are becoming more and more aware of the issue. These concerns among the general public have led to the development of policies so as to ensure that countermeasures are in place to minimize the adverse environmental impacts of industrial activities. 
These policies, which are often referred to as green policies, influence firms, companies, and even small business owners that own assets or fleets of assets. Most businesses deal with assets that have emissions associated with, usually, they at least own vehicles that are used in transportation. Now with the green policies in place, whether corporations or asset owners have environmental concerns themselves or not, they are impacted by such policies. This means that there is a new dimension being added to classical asset management problems. Now the firms that own fleets of assets need to also minimize the emissions and pollutions caused by their activities along with minimizing the cost.

Although asset management has vast applications in a variety of industries, such as logistics and transportation, construction, manufacturing and mass production, military, health care, et cetera, the reality is that in many cases, firms, companies, and owners of fleets of assets do not take advantage of scientific approaches, statistical analyses, or mathematical models to utilize their assets optimally. In many cases, the assets are repaired or replaced once they are out of order, and many companies almost never conduct studies to see whether replacing or improving an asset is financially beneficial. The mentality in most instances, especially for the smaller businesses, is "if it is still working, why would you replace it?". Let alone examining the environmental aspects of such considerations. In the rarer cases where there is a replacement cycle and a schedule in place, it is mostly limited to the concerns of the downtime and the financial aspect of the replacement. However, with the carbon pricing in place, the asset managers will pay money for their emissions one way or the other.

Thus, there seems to be a need to move towards taking the environmental aspect of the asset management into account. In the next section, the issue of global climate change and the 
countermeasures developed around the world are presented, and there will be a short review of the environmental policies in Canada. Later, it will be discussed how these policies might affect the study of parallel assets management.

\subsection{CARBON PRICING AND EMISSIONS TRADING}

\subsubsection{Overview}

With the massive expansion of mass-production and industrial-scale manufacturing, industrial activities are known to be one of the main causes of emitting massive amounts of various emissions in the atmosphere. These emissions and pollutants are scientifically believed to be related to the issue of global climate change (Stocker, 2014).

Figure 1.1 Nanticoke Generating Station, the largest coal-fired power plant in North America which turned into a solar plant and started working in April 2019 ("Former coal-fired power plant in Ontario becomes solar facility," 2019)

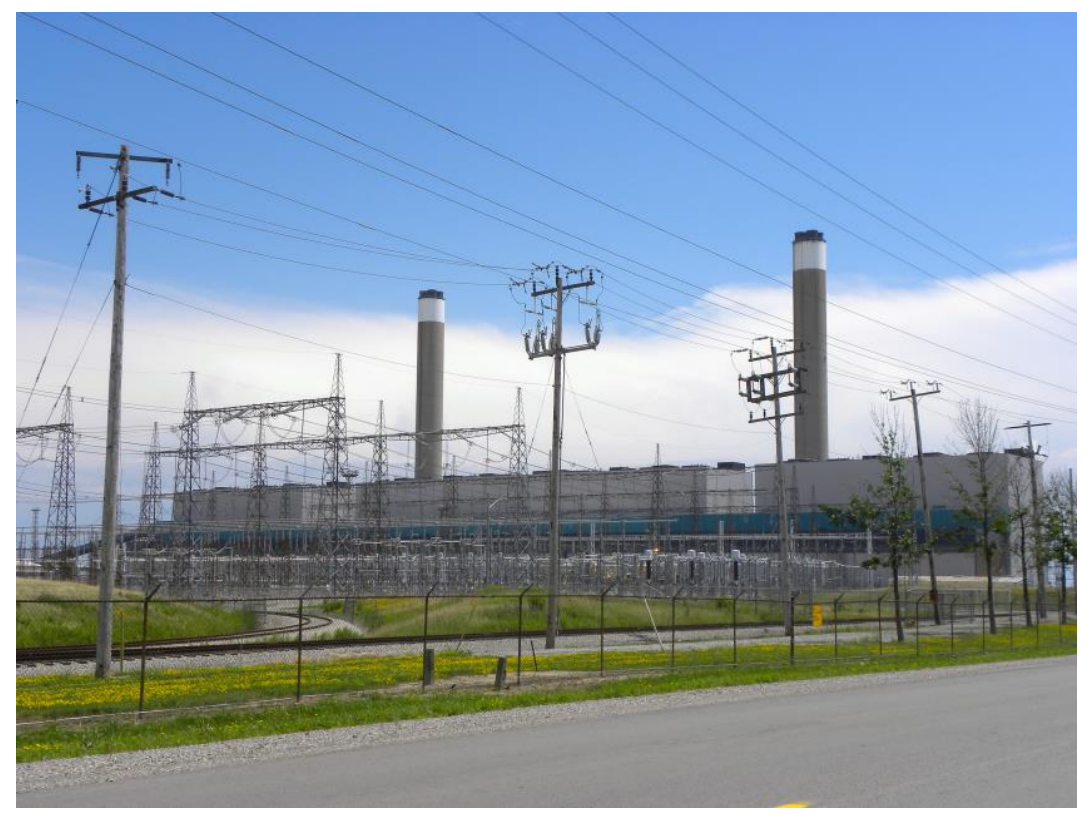


Government of Canada considers climate change to be one of the most significant environmental issues of the time (Canadian Environmental Sustainability Indicators: Greenhouse gas emissions, 2018). Both the federal and provincial governments have developed and implemented plans to control GHG emissions. Figure 1.2 shows the trend of GHG emissions in Canada since 1990 by sector. Physical asset management and parallel management of fleet of assets are directly and closely related to the sectors of heavy industries, agriculture, transportation, and oil and gas. However, asset management might be applicable to the other sectors in many cases as well.

Figure 1.2 GHG emissions by sector since 1990 (Canadian Environmental Sustainability Indicators: Greenhouse gas emissions, 2018)

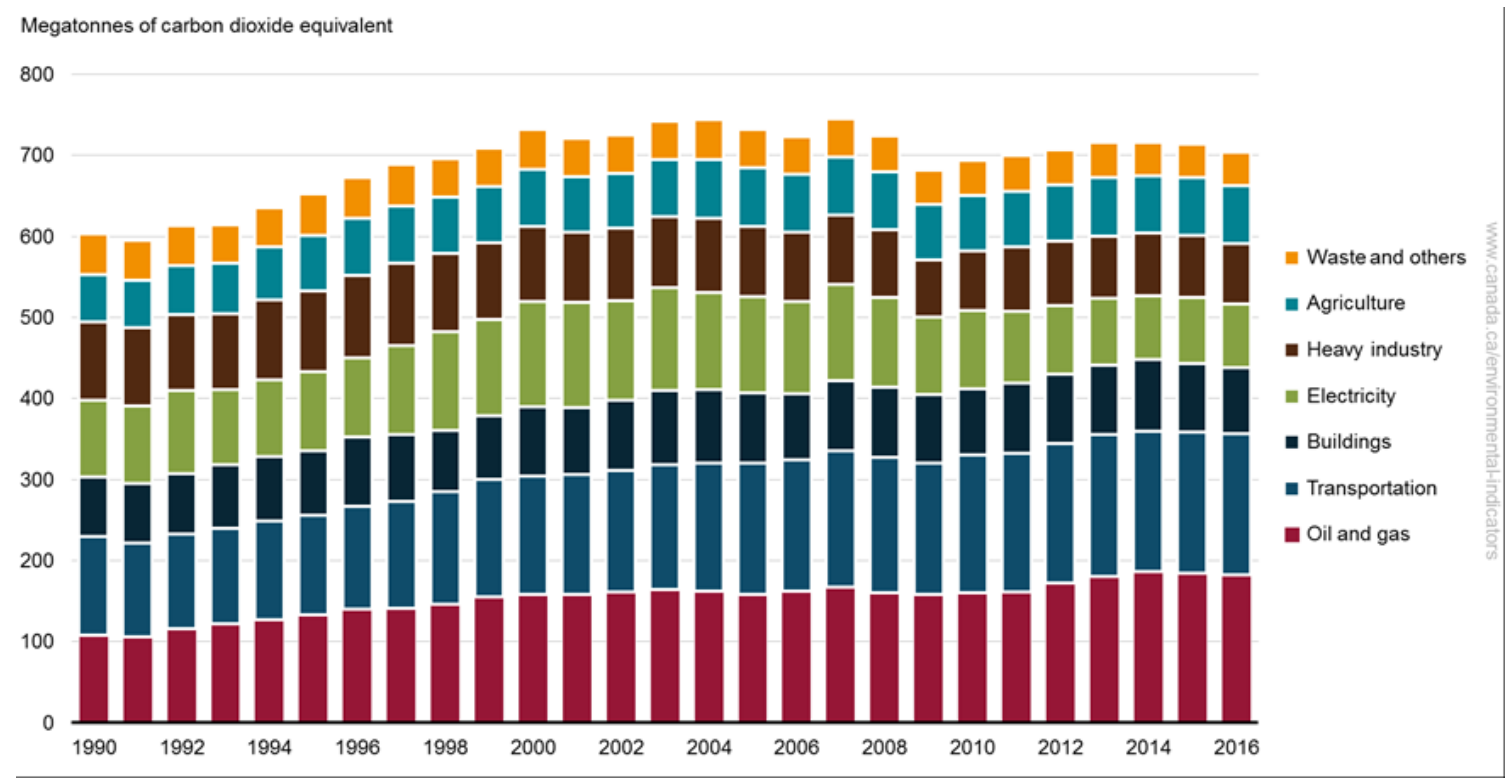

One of the ways to confront the abovementioned issue is to embark on carbon pricing strategies to control, limit, and reduce the amount of GHG emissions. Since the ("UNFCCC," 1992) was signed and later followed by other treaties such as the ("Kyoto Protocol," 1997) and 
the ("Paris Agreement," 2015) to expand it, many federal and provincial governments around the world have proposed carbon pricing strategies. The main two forms of carbon pricing are carbon tax and emissions trading system (ETS). The latter is also known as cap-and-trade. Figure 1.3 maps an overview of carbon pricing methods deployed all over the globe.

Figure 1.3 Overview of carbon pricing strategies around the world (Kossoy, 2015)

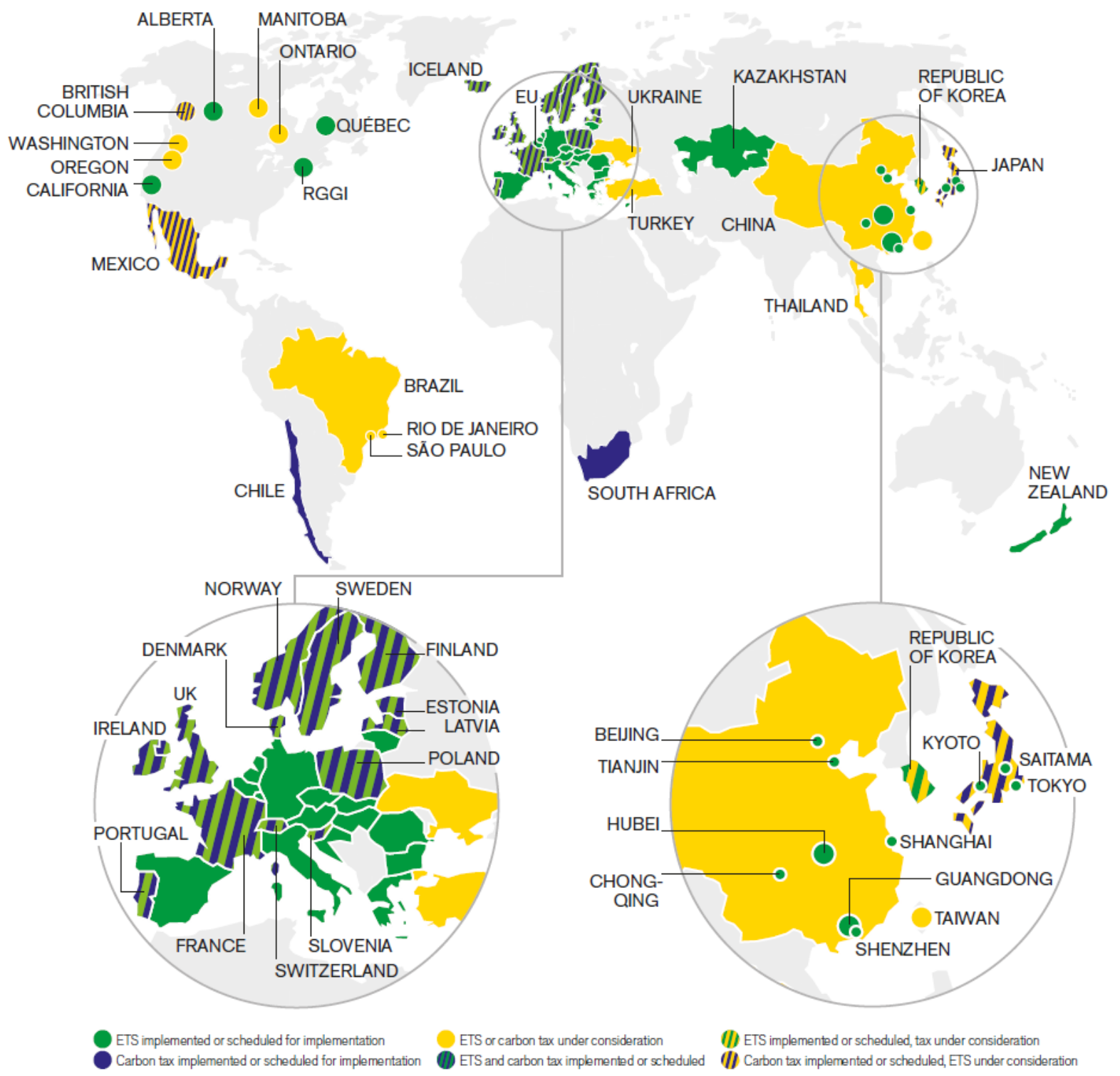


Moreover, (Kossoy, 2015) argues that the means of controlling GHG emissions have shown to be effective and in the last decades, the strides which have been made have resulted in planning to take control or taking control of more than 35 percent of the global GHG emissions. Figure 1.4 illustrates the trend of covering global GHG emissions since 1990. This shows the importance of carbon pricing policies in the future of asset management studies, as the trend seems to be in the direction of covering more portions of industries around the globe in future. 
Figure 1.4 Percent of the global GHG emissions covered by carbon pricing schemes (Kossoy, 2015)

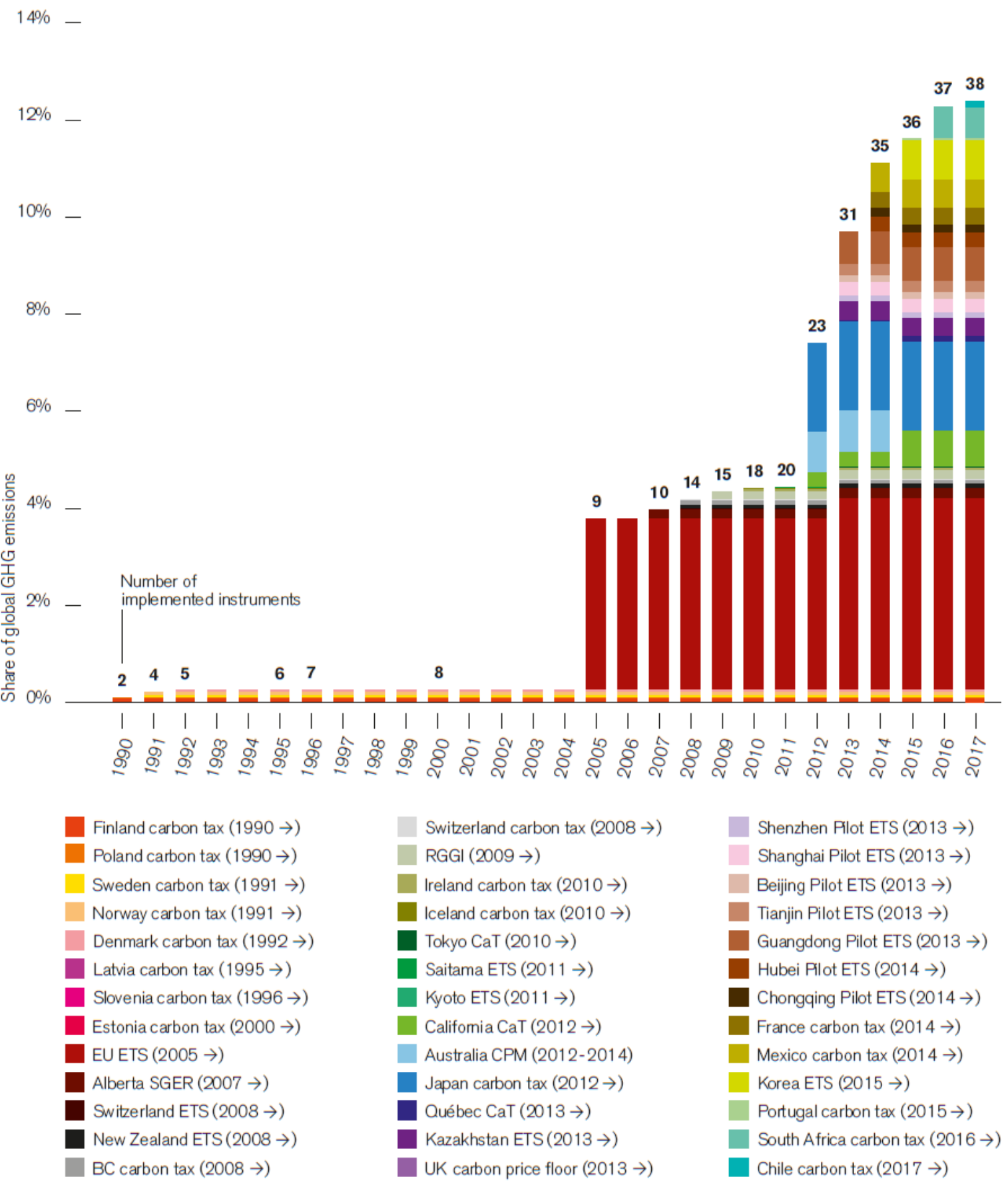

Finland carbon tax $(1990 \rightarrow)$

Poland carbon $\operatorname{tax}(1990 \rightarrow)$

Sweden carbon tax $(1991 \rightarrow)$

Norway carbon tax $(1991 \rightarrow)$

Denmark carbon tax $(1992 \rightarrow)$

Latvia carbon $\operatorname{tax}(1995 \rightarrow)$

Slovenia carbon tax $(1996 \rightarrow)$

Estonia carbon tax $(2000 \rightarrow)$

EU ETS $(2005 \rightarrow)$

Alberta SGER $(2007 \rightarrow)$

Switzerland ETS $(2008 \rightarrow)$

New Zealand ETS $(2008 \rightarrow)$

BC carbon tax $(2008 \rightarrow)$

Switzerland carbon tax $(2008 \rightarrow)$

\section{RGGI $(2009 \rightarrow)$}

Ireland carbon tax $(2010 \rightarrow)$

Iceland carbon tax $(2010 \rightarrow)$

- Tokyo CaT $(2010 \rightarrow)$

Saitama ETS $(2011 \rightarrow)$

Kyoto ETS $(2011 \rightarrow)$

Califomia CaT $(2012 \rightarrow)$

Australia CPM (2012-2014)

Japan carbon $\operatorname{tax}(2012 \rightarrow)$

Québec CaT $(2013 \rightarrow)$

Kazakhstan ETS $(2013 \rightarrow)$

UK carbon price floor $(2013 \rightarrow)$

Shenzhen Pilot ETS $(2013 \rightarrow)$

Shanghai Pilot ETS $(2013 \rightarrow)$

Beijing Pilot ETS $(2013 \rightarrow)$

Tianjin PilotETS $(2013 \rightarrow)$

Guangdong Pilot ETS $(2013 \rightarrow)$

Hubei Pilot ETS $(2014 \rightarrow)$

Chongqing Pilot ETS $(2014 \rightarrow)$

France carbon tax $(2014 \rightarrow)$

Mexico carbon tax $(2014 \rightarrow)$

Korea ETS $(2015 \rightarrow)$

Portugal carbon tax $(2015 \rightarrow)$

South Africa carbon tax $(2016 \rightarrow)$

Chile carbon tax $(2017 \rightarrow)$ 


\subsubsection{Carbon tax}

As a sort of Pigouvian tax, the levied on the carbon content of fuels, hinders the industries from discharging carbon dioxide through cost-effective means. A carbon tax, as its name implies, is a tax put on the fuels etc. based on their carbon content (Hoeller \& Wallin, 1991). Normally, other GHG emissions are converted to their carbon equivalent and are noted as $\mathrm{CO}_{2} \mathrm{e}$. A carbon tax can be a regressive tax, increasing in price for the increase of emitted pollution. This system is used throughout many nations worldwide, although industrial countries such as the US, China and Russia are still having doubts and debates in regard to passing such legislation. The goal of the carbon tax is for the GHG producers to pay for the Social Cost of Carbon (SCC), which is the marginal cost of the impacts caused by emitting one extra ton of carbon on the environment and human health. Therefore, such cost must be estimated, through estimating the residence time of carbon dioxide in the atmosphere, along with estimating the impacts of climate change.

\subsubsection{Emissions trading systems}

One of the first countries to use a cap-and-trade system to control a pollutant was the US for the case of Sulphur dioxide $\left(\mathrm{SO}_{2}\right)$. Executed under the framework of the Acid Rain Program of the 1990 Clean Air Act, the program was considered a success reducing $\mathrm{SO}_{2}$ emission by $50 \%$ from 1980 levels by 2007 (Ellerman, Joskow, Schmalensee, Bailey, \& Montero, 2000). Following that program, cap-and-trade was used to reduce other gas emissions such as nitrogen oxides ran by the Environmental Protection Agency (EPA) under $\mathrm{NO}_{\mathrm{x}}$ Budget Trading Program, but despite decades of debates and efforts, the same has never been gone for the GHGs' reduction federally in the United States. Although, legislation was passed in some states involving New York and California 
to control global warming mostly with regard to carbon dioxide discharge (Aulisi, Farrell, Pershing, \& VanDeveer, 2005; Farrell, Carter, \& Raufer, 1999; Turin, 2012).

Multiple emissions trading systems have been designed and implemented on international, national, and sub-national scales so far. The European Union Emissions Trading Scheme (EU ETS) was the first and so far, is the biggest international cap-and-trade market in the world since it was established in 2005, beginning its first phase in 2005 after voluntary trials in the UK and Denmark. In the first two years of run, the emissions reduction was not significant due to the oversupply of allowances. These flaws were treated in the second phase of the scheme. Norway, Iceland, and Liechtenstein later joined the EU ETS in 2008 (Building a low-carbon economy-the UK's contribution to tackling climate change, 2008; Skjærseth \& Wettestad, 2016; Zhang \& Wei, 2010).

In this thesis, we will focus on the California and Quebec cap-and-trade market. California and Quebec, two of the jurisdictions participating in Western Climate Initiative, started a linked emission trading system which was later joined by the province of Ontario (Purdon, Houle, \& Lachapelle, 2014). However, by the time this thesis is being written, the cap-and-trade system in Ontario has been shut down.

An emissions trading system is a way of setting a limit over the amount of GHG emissions while letting the firms affected by the regulation to find the most efficient way for them to reduce their emissions. This aim will be achieved by allowing emitters to trade emission allowances, or carbon allowances, as other emissions are usually measured by their carbon equivalent. Carbon allowances or permits are given by the governmental authorities to the emitters. The allowances indicate how much emission a participant is permitted to emit. The participants then could buy or 
sell permits based on whether they have managed to reduce their emissions in each year or not (Stavins, 2003). Figure 1.5 shows a schematic picture of how the cap-and-trade scheme works.

\section{Figure 1.5 Emissions trading system (A Brief Look At The Quebec Cap-And-Trade-System For Emission Allowances, 2018)}

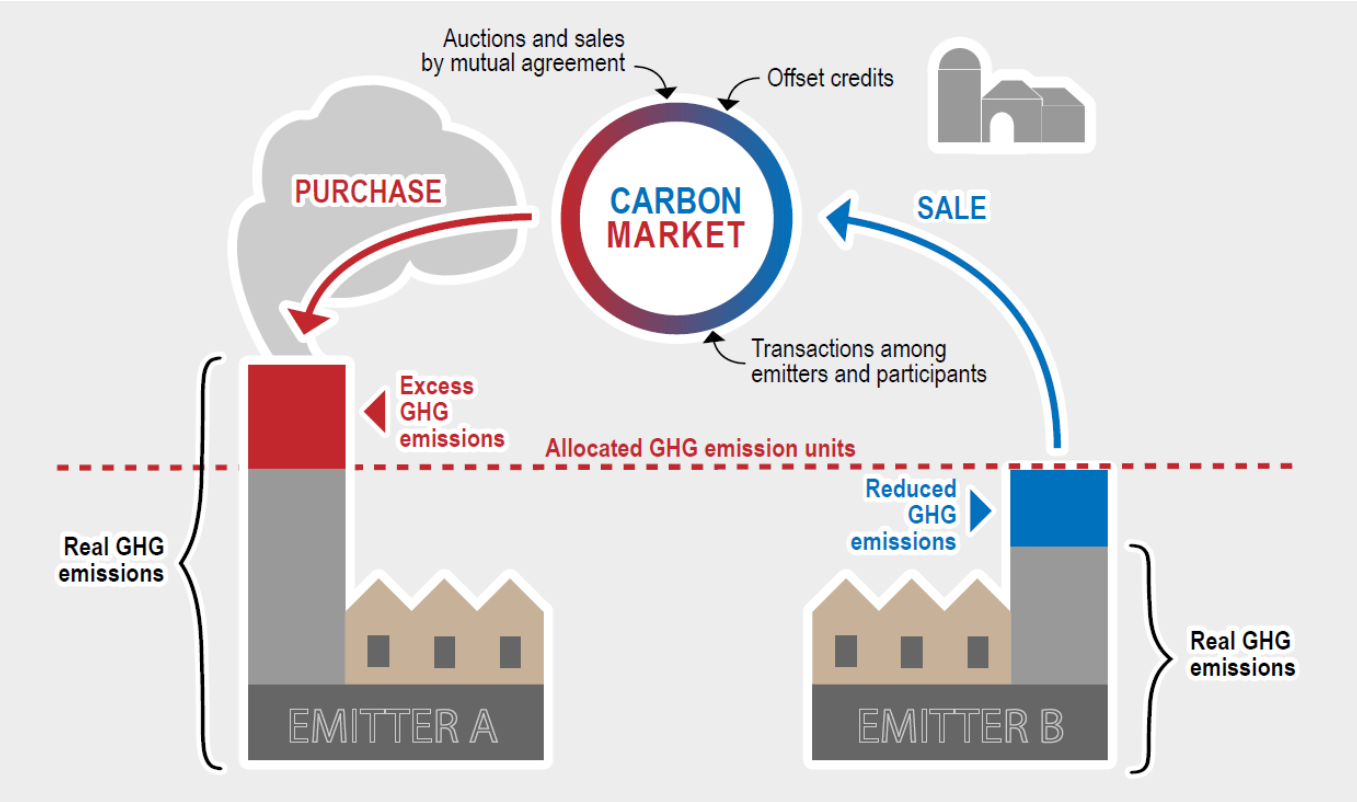

The governmental body that imposes cap usually lowers the cap incrementally to achieve a desired level of emissions over time. For example, the government of Quebec rules that in the year 2018, the total amount of GHG emissions should be less than 60 million tons of emissions. Now, the market will balance the emissions using the premise of supply and demand to help all the emitting firms to achieve the goal of reducing the total emissions under the desired level. The cap in most cases will be designed to be lessened year by year so that over the span of a decade it could reduce the amount of emissions significantly. In Figure 1.6, the levels of the cap imposed by the government of Quebec from 2013 to 2030 have been shown and the incremental decrease could be observed. 
Figure 1.6 cap on GHG emissions set by the Government of Quebec (A Brief Look At The

Quebec Cap-And-Trade-System For Emission Allowances, 2018)

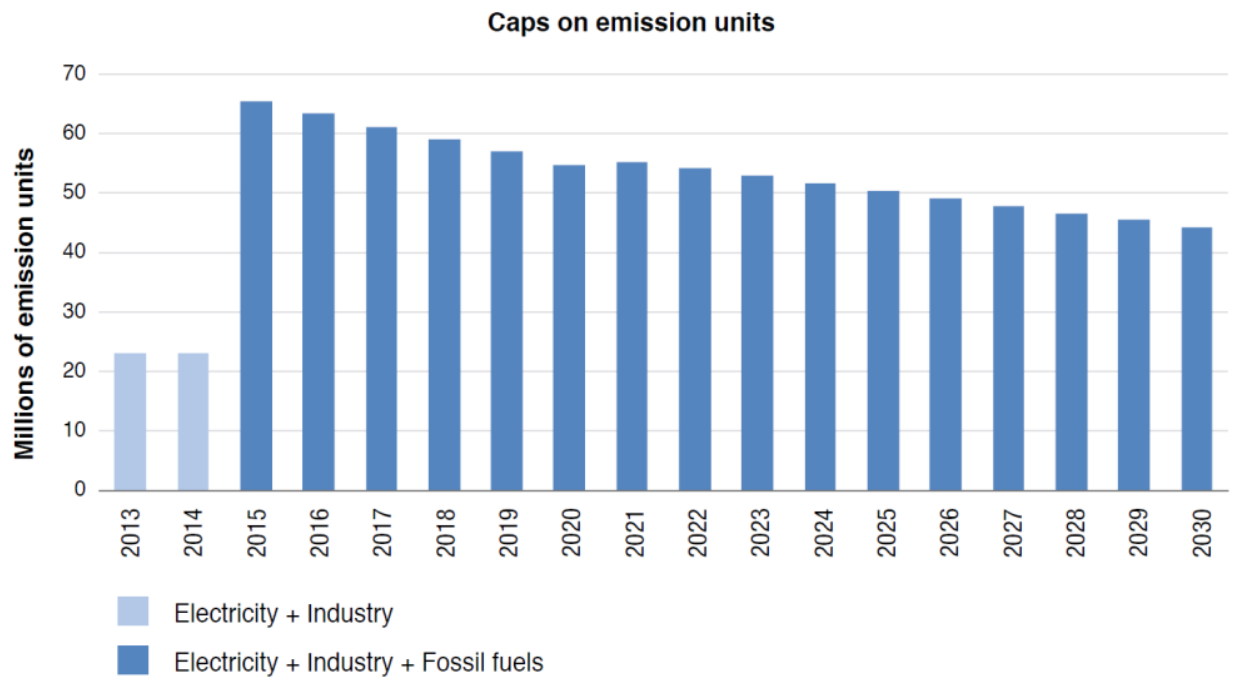

\subsubsection{Carbon tax vs. cap-and-trade}

The two strategies have been widely discussed and compared. For instance, few differences have been enumerated between them by (Wittneben, 2009). Firstly, it is mentioned that in carbon tax strategy there is no upper limit for the emissions, and they are reduced as long as the tax price exceeds the cost of emission reduction. Therefore, companies which can afford the taxes will continue to emit despite the levied taxes. In cap-and-trade though, the total emission is limited and there is a zero-sum trade. The second difference is the government income from each strategy. As for the carbon tax, the pricing is set and the total income is determined by the activity of industries, decreasing in times of depression, the income from cap-and-trade is determined by the auctions since the allocated amounts are predetermined and limited. Next, the cost of each has been considered to the public, which for a carbon tax is no more than any other tax and the mechanisms are already established, for cap-and-trade though, new markets must be established, and people and financial institutions must be hired as meditators at the cost of the public purse. 
It is also necessary to briefly discuss the current state of carbon pricing policies in Canada. Although Canadian provinces and territories are able to develop their own system of carbon pricing that suits their specific needs, the government of Canada has passed a bill in December 2018 to make sure all the provinces and territories meet the federal requirements of carbon pricing (Implementing Canada's plan to address climate change and grow the economy: Putting a price on carbon pollution, 2018).

Quebec was the first province to put a price on carbon in 2007. Most other provinces also developed carbon pricing systems, either carbon taxes or cap-and-trade. However, Ontario, Manitoba, and New Brunswick later opted out of the carbon pricing scheme. With the new legislation, however, all Canadian provinces will have to adhere to some sort of carbon pricing.

Ontario's cap-and-trade regulation came into effect in 2016 after joining the CaliforniaQuebec ETS market. After the change of the provincial government, the program was shut down in July 2018 (The cap and trade program, 2016).

In the next section, it will be shown that how these carbon pricing policies will affect the parameters of decision-making regarding asset management, and it will be explained that there is a new dimension being added to the classic asset management approach.

\subsection{PARALLEL ASSET MANAGEMENT}

\subsubsection{Overview}

After explaining the concern of the global climate change, the global and Canadian policies to confront the issue and the statistics that indicate the significance of the problem, it is needed to 
examine the relationship between these carbon pricing policies and asset management.

As the green policies are flourishing and developing, they seem to expand to new fields rapidly and sometimes change the approach of thinking and the direction of the research entirely. In the case of asset management, there is definitely a significant and measurable relationship with the emissions pricing. Most assets used in industry emit GHG emissions to the atmosphere and those which do not, have GHG emissions associated with the process of manufacturing them, the process of transporting them, and their maintenance.

The emissions associated with industrial activities are often segmented into three scopes. Scope 1 emissions are those that are directly caused by an activity or a series of activities by a firm. Scope 2 emissions are those that are caused as a result of purchasing electricity, steam, heating, cooling, etc. Scope 3 emissions are the emissions that are caused by business activities such as leased assets, employee commuting, business travels, and emissions associated with purchased commodities, transportation, and so forth.

This outlook towards emissions transcends the classic view that considers the emissions of a company to be just the smug coming out of the stacks. This approach shows that not only does a fleet of buses or trucks have emissions associated with it, but also a network of computers has emissions associated with it since it uses electricity and the manufacturing of those computers could pollute the environment. Hence, there is a need for the incorporation of environmental factors in asset management. 


\subsubsection{Terminology and background}

In this thesis, the focus of study is on parallel asset management. It is necessary to first clarify what physical asset management is, and next to distinguish parallel asset management, and finally to mention the definition of some of the terminology used in the topic.

Asset: An asset is a physical resource owned and controlled by an entity. This entity could be an individual or a firm or corporation. Some examples of assets could include equipment, installations, property, vehicles, etc. Figure 1.7 shows some examples of assets (Hastings, 2010).

Figure 1.7 A manufacturing machine, an excavator, and a building. All examples of assets. (Rezwan, Pixabay, \& Skitterphoto)

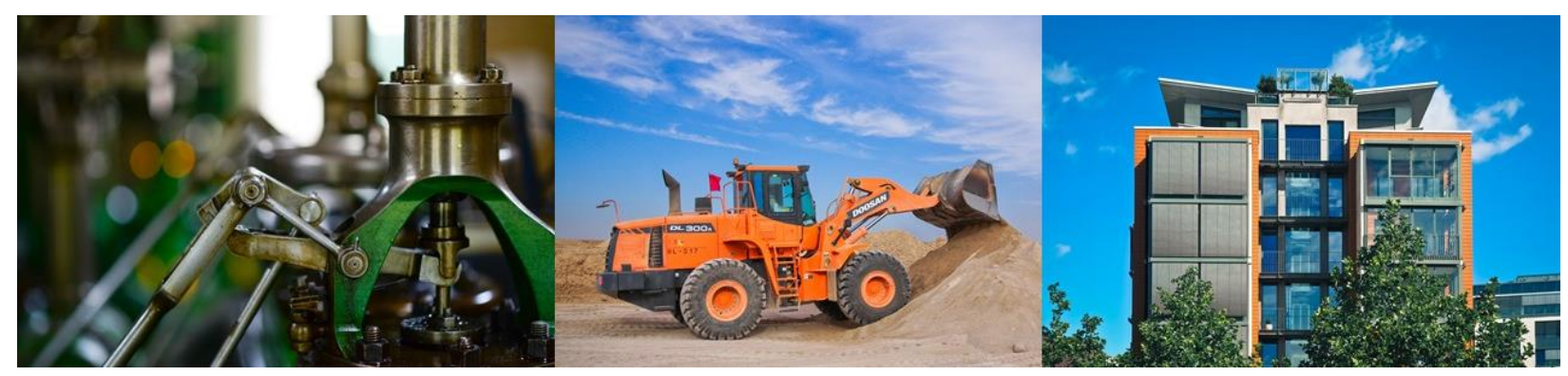

Physical asset management: It is the systematic process of governing the current assets of a company. It could entail the process of maintenance of an existing asset, purchasing new ones, modifying current assets, selling, or salvaging them (Hastings, 2010).

Salvaging: Salvaging is the act of selling an asset after its maximum utilization time or once its economic lifetime is over. Salvaging an asset is different from selling, in the sense that the salvage price of an asset is usually equal or less than the value of its material, e.g. the price of steel used in a lathe machine. 
The general research on asset management goes back to when (Taylor, 1923) studied the depreciation problem and its impact on the value of assets. The classic replacement problem and economical lifetime which together form the foundation of asset management include an optimization model to contemplate the use of an asset that is currently working and analyze the proper time to replace it with a new asset. Traditionally, the asset which is currently being utilized is referred to as the defender and the new asset by which the defender could be potentially replaced by, is referred to as the challenger. The traditional replacement models normally consider the two options of replacement or continuing the use of an asset in each period (Fraser \& Posey, 1989). There are many papers and case studies that have conducted comprehensive research around this topic. Some of the more recent works are presented in Chapter 2.

It has been of the concern of all asset owners that when is the proper time to replace an asset or a component. This question is not just limited to enormous industrial manufacturers or construction project managers. Even from a household or personal perspective, a car owner is interested to know when the best time is to change a component, or basically what the most costefficient lifecycle of that component is. Or on a broader scope, the car itself.

Parallel asset management: Parallel asset management is the process of physical asset management when instead of having one asset, there are multiple assets that are doing a similar job. The assets might have different performances and properties, yet their function is similar, and in some cases, they might be able to substitute for one another. The process of utilizing such sets of assets - also referred to as fleets of assets - is commonly known as parallel asset management. Essentially, this means that instead of one defender, there are multiple defenders which are doing a similar job and might potentially replace one another in some cases (Hastings, 2010). 
There is a myriad of examples for a fleet of assets working in parallel. To name a few:

- Components in a machine that perform the same function.

- Computers working in a network to do the same task.

- A fleet of buses in a public transportation organization.

- A fleet of trucks or excavators in a construction site

- MRI devices in a big hospital.

- $\mathrm{CNC}$ machines in a fabrication plant.

- Forklifts in a warehouse.

This list could go on for pages. This shows the significance and relevance of the parallel asset management and its vast use in the industry both from a risk management perspective (downtime), a financial perspective, and last but not least, the environmental perspective.

Figure 1.8 A fleet of buses used in urban transportation. (Imre)

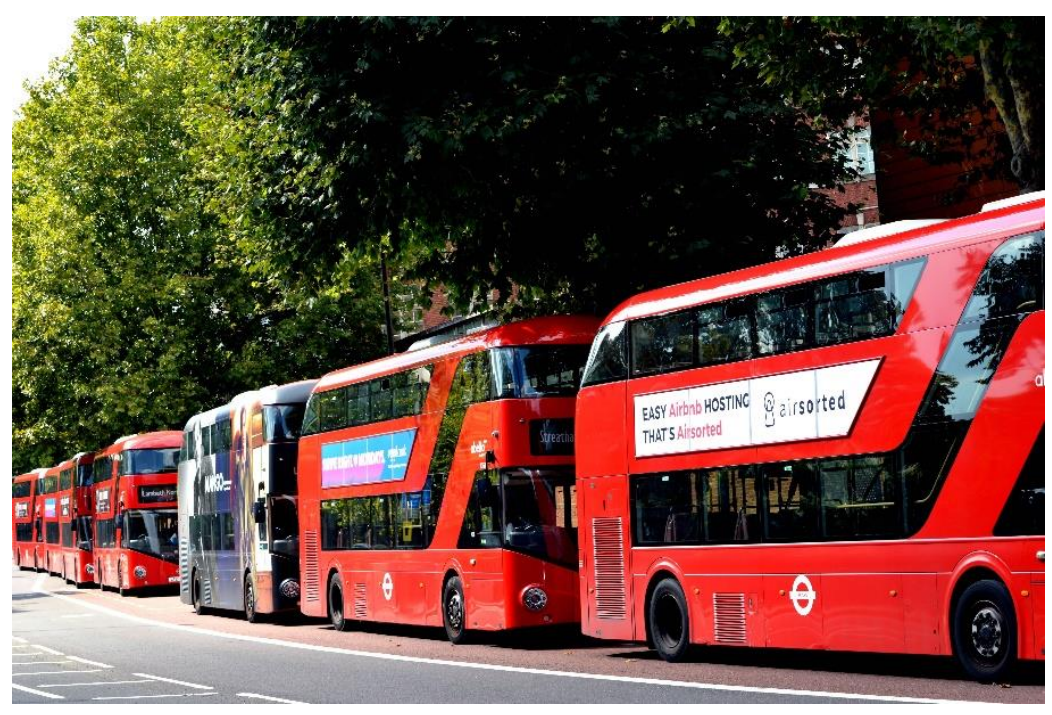




\subsubsection{Retrofit}

One of the contributions of this thesis is to consider technological retrofit or enhancement for the assets. It is appropriate to explain what technological enhancement means. Any change such as the addition of a component or replacing a component with a higher-performance component could be considered as retrofit. This enhancement might be a comprehensive change done by the original manufacturer to improve the performance of a machine, or simply adding a small component that improves a particular function of a device. For example, if the manufacturer of a CNC machine offers a new software update for their machines, this could be an option of retrofit for the asset owners. A simpler example could be adding a sensor to a silicone pump in a glazing company in order to stop the pump automatically once the pump runs out of silicone. Any of these improvements, whether they are simple or of a larger scale and complexity, they could result in the reduction of waste and possibly lowering the emissions of assets. With this broader definition of retrofit or technological improvement, almost all owners of fleets of assets will deal with some sort of retrofit in the process of managing the assets. Figure 1.9 shows a silicone pump used in glazing. 
Figure 1.9 A silicone pump, adding a sensor to stop the flow once the pump runs out of silicone is an example of how retrofit results in waste reduction ("Dow Corning Silicone Pumps, "2019)

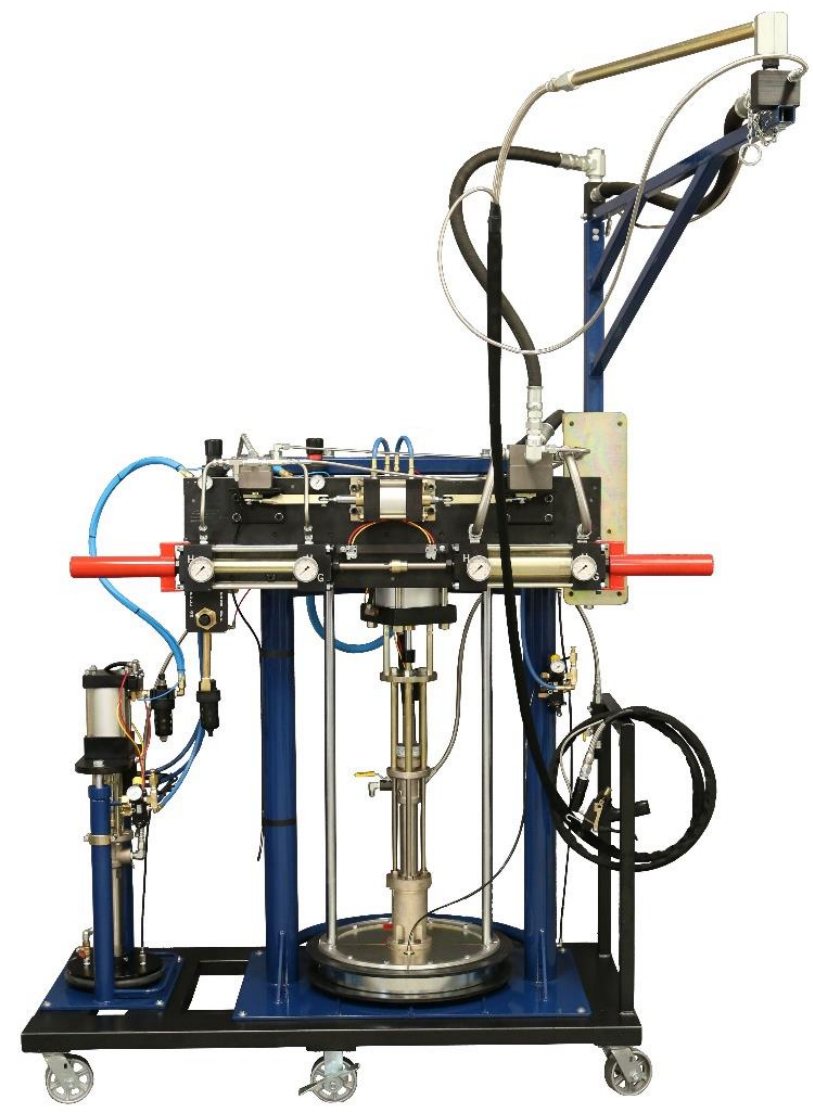

Now that the terminology is explained and background of the parallel asset management is covered, it is appropriate to show how the green policies and specifically carbon pricing will impact parallel asset management. Therefore, in the next section, the motivation of this research will be explained, and the scope of the work will be presented to clarify what is included in the considerations of this work and what is not.

\subsection{RESEARCH MOTIVATION AND SCOPE}

Companies, organizations, and small businesses in jurisdictions where carbon pricing exists now must look after their GHG emissions. In Canada, as explained earlier, all provinces are now 
influenced by a form of carbon pricing. It is believed that the cap-and-trade system has more complexity in its nature compared to a carbon tax, and thus, businesses will have to use more scientific approaches to manage their assets under cap-and-trade regulations. This formed the basis of the motivation to start this research.

Moreover, in many cases, simple retrofit and enhancement could result in significant emissions reduction in the real world. Hence, it seems apt to include the option of retrofit in any study that aims to aid firms with the management of their assets.

The scope of this work includes parallel asset management, the model will include a fleet of assets that work in parallel. Out of all environmental concerns, we only focused on GHG emissions and did not consider other pollutants or forms of waste or other adverse impacts of industrial activities. Options of purchasing new assets, utilizing current assets, improvement, storing the assets, and salvaging them were considered. As it will be explained in Chapter 3 , the option of retrofit in the model is designed so generically that it could be applied to virtually all real-world cases.

\subsection{RESEARCH GAP}

Although there are works in the field that study the ecological aspects of the parallel asset management in order to help firms utilize their assets optimally, there seems to be an inadequacy with regard to parallel asset management under cap-and-trade regulations. In other words, the models and works that study the parallel asset management under the regulations of emissions trading markets appear to be extremely limited. Nonetheless, emissions trading systems and markets have existed for a while and seem to prevail in the future. 
This shows a big opportunity for researchers. Much research could still be conducted on the modelling of optimal asset management, parallel asset management, and the replacement problem in jurisdictions where GHG emissions are regulated by cap-and-trade. Moreover, the impact of different cap-and-trade regulations could be of interest, especially with a sensitivity analysis approach.

\subsection{RESEARCH OBJECTIVES}

After explaining the current state and the research gap, the next step is to explain the goals of this thesis. The main objectives of this research are the following:

1. Developing an optimization model based on operations research to model the parallel replacement of a fleet of assets, while minimizing both the costs of the asset and the environmental factors. The model should entail the according factors that simulate the circumstances caused by regulations of a cap-and-trade system. The model is designed to be as generic as possible to be compatible with various real-world problems.

2. Application of the model using the data from a fleet of excavators in Ontario under the regulations of California-Quebec cap-and-trade system.

3. Conducting sensitivity analysis to examine the reactions of the case study's results caused by the changes in the circumstances and the input data.

4. Proposing suggestions about requirements of proper deployment of this model.

In this research, a mathematical model is developed. The mixed-integer approach was opted owing to the nature of the problem and the according constraints. The model was solved, 
and an exact optimal solution was derived in each step.

\subsection{THESIS OUTLINE}

This thesis entails a broad range of information concerning the economic and environmental aspects of the problem. The work also includes a comprehensive literature review to explain the general atmosphere in the literature and the trend of research around the problem. Equations and tables are a natural part of works that involve a mathematical model, and in this work, they are followed by a full explanation. This thesis is structured in the way below:

Chapter 1 introduces the fundamentals of the work, the methodology and the objectives.

Chapter 2 includes a review of the literature.

Chapter 3 explains the problem thoroughly, involves the assumptions, and presents the mathematical model.

Chapter 4 presents both the numeric results of the case study and the analysis of sensitivity and explains the conclusions that could be possibly made based on the results.

Chapter 5 summarizes the findings of this research and suggests opportunities for future research. 


\section{LITERATURE REVIEW}

\subsection{REPLACEMENT PROBLEM}

Assets degrade as a result of utilization and ageing, and consequently, an increase in operation and maintenance costs and potentially more greenhouse gas emissions could be expected. Therefore, It is economically reasonable to replace assets after a while (Verheyen, 1979). Moreover, newer assets and more advanced technologies might be available in the market. Thus, firms and companies are usually involved and interested in detecting the apt time to replace their assets (Fan, Machemehl, \& Kortum, 2011), because right timing will potentially decrease their costs and mitigate their carbon footprint.

The study of parallel asset management could be especially useful for sustainable cities, as many organizations in a city deal with a fleet of assets on a daily basis, whether it be a fleet of excavators used in the construction sector or a fleet of vehicles working in the transportation sector. In addition to the general environmental concerns, emissions in urban areas are also associated with public health risks (Sydbom et al., 2001). Therefore, the sustainability factors in the management of a fleet of assets - which as explained later adds to the novelty of this work - should be more of interest for a firm or organization that works in urban areas.

In this work, we developed a mixed integer model for the parallel replacement problem under technological change while also considering the environmental aspect of the problem where the emissions are regulated by a cap-and-trade system. The parallel replacement problem could be taken advantage of by a variety of industries. It could be applied to a network of computers working 
in parallel to provide a certain service in IT sector, a set of lathes in a manufacturing firm, or as we considered in our case study, a fleet of excavators in a construction project.

\subsection{PAPERS CONSIDERING ECONOMIC FACTORS ONLY}

There are multiple papers which have studied the replacement problem since (Terborgh, 1949) first studied the optimal time to replace an asset that is being used. However, most of the older and classic papers have mainly focused just on the economic aspects of this problem. For instance, (Derman, 1963) modelled the replacement using Markov chains, and later, (Hatoyama, 1984) expanded the use of Markov chains in the replacement problem. (Vander Veen \& Jordan, 1989) for the first time stated that the purchase and utilization of assets are related and modelled them together in their model. A thorough review of classic replacement problems and models related to that is contained in (Jardine \& Tsang, 2013) and (Feldman \& Valdez-Flores, 2014).

The classical replacement model, as the word replacement indicates, mostly focuses on replacing an existing asset with a new one. In this work's model, however, we considered the option of technological enhancement or in other words, retrofit of an existing asset, in addition to replacing it with a new one. There are precedents of such consideration in the literature. (Meyer, 1993) pointed at the significance of extending the conventional replacement models and considering technology enhancement in the models. Later, (J. Hartman \& Ban, 2002) presented a model for a series-parallel replacement model and considered different characteristics for different types of assets in addition to considering a general technological improvement. Afterwards, (Regnier, Sharp, \& Tovey, 2004) developed a deterministic model for a single asset under continuing technological change. More recently, (Yatsenko \& Hritonenko, 2017a) studied serial 
replacement of a single asset with two different approaches and compared the results under exponential technological improvements and stochastic cost change.

Furthermore, (Yatsenko \& Hritonenko, 2011) studied the economic lifetime of assets under technological improvement and argued that the economic lifetime approach works when the rate of change in technology is low. They also suggested that on the other hand, if the rate of technological change is higher, it could be recommended to use the two-cycle method. Same authors further studied the two-cycle approach in (Yatsenko \& Hritonenko, 2017b). The two-cycle method had been developed by (Christer \& Scarf, 1994) and further studied in (P. Scarf \& Hashem, 2002; P. A. Scarf \& Hashem, 1997). The two-cycle method basically minimizes the yearly cost for the next two replacement cycles, as opposed to the entire problem horizon. Later, (Mardin \& Arai, 2012) expanded the two-cycle approach through consolidating an annual discount rate, and contended that their method betters the conventional challenger-defender, and in some instances, the economical lifetime approach.

In this thesis's model, there are different types of assets available for purchase when an existing asset is going to be replaced. Similar to this, (Büyüktahtakın, Smith, Hartman, \& Luo, 2014) studied the replacement problem with multiple challengers and presented the option of different asset types for challengers. Later in (Büyüktahtakın \& Hartman, 2016), they suggested a mixed-integer model for replacement of a fleet of assets working in parallel under technological change. 


\subsection{PAPERS INCLUDING ENVIRONMENTAL AND ECONOMIC FACTORS}

In more recent literature, still, there is a general opportunity to work more on taking environmental factors into consideration and incorporating them in the optimization models. There are many papers that study the problem with a major focus on the economic aspects of it. For instance, $(\mathrm{He}$, Fan, $\mathrm{Li}, \& \mathrm{Li}, 2017)$ studied the replacement of fuel-consuming vehicles with hybrid electric vehicles and examined the impact of fuel price and subsidies on the decision using dynamic programming. Although their work is related to the replacement of emitting vehicles with a greener solution in general, they do not concentrate on sustainability factors per se in their model. Later on, (Ngo, Shah, \& Mishra, 2018) investigated the allocation of the governmental budget on a fleet of buses with different objective functions. They considered options of rehabilitation and remanufacturing in addition to replacement of the assets. Similarly, (Riechi, Mácian, Tormos, \& Avila, 2017) argued that stochastic models are more effective and accurate to use for a fleet of vehicles taking into account the fact that variations are a natural characteristic of vehicles. They used their stochastic model in a case study of a fleet in Spain to prove their point. Also, (Wang \& Nguyen, 2017) investigated the economic lifetime and replacement of existing technology with consideration of different available technologies to opt, capacity and demand and (Zheng \& Chen, 2018) studied fleet replacement under uncertain fuel prices and uncertain demand for a ship owner. Although the latter paper touches emission control policies, which are not particularly GHG emissions, and their impacts on the ship owner's replacement decisions, the focus of the paper remains on the economic aspects of the replacement timing decisions.

It seems that there is insufficient work in the literature about environmental impacts of replacement decisions and asset management. Nonetheless, there are some works in the recent 
literature that proposed models including environmental factors. For instance, (de Macedo, de Miranda Mota, \& Sola, 2018) used multicriteria decision analysis to establish a model for motor replacement so as to help a firm fulfil the efficient energy requirements in Brazil, and (Yuan, Zhang, Wang, Liang, \& Zhang, 2019) conducted a comprehensive study on urban bike sharing systems and developed a master model using mixed integer linear programming method to solve multiple sub-problems of the system like capacity, location, fleet size, and so forth.

Moreover, (Afrinaldi, Tasman, Zhang, \& Hasan, 2017) proposed a model using a Genetic Algorithm to optimize preventive replacement schedule of a component and pondered environmental factors in their model. Also, (Feng \& Figliozzi, 2013) used an optimal replacement model to study the competitiveness of electric commercial vehicles compared to diesel trucks and incorporated GHG emission parameters in their model. Similarly, (Ahani, Arantes, \& Melo, 2016) developed an optimization model to find the optimal combination of electric vehicles and internal combustion engine vehicles in cities and urban areas using a portfolio theory and reflected on the uncertainty of parameters and risk assessment of the scenarios. They also considered emission factors in their model.

(Abdi \& Taghipour, 2018) Studied the replacement model under the regulations of capand-trade. They also provided a probabilistic model to predict the price of carbon in the market. However, they did not consider different technological types in their work, in spite of assuming that the technology will improve over time naturally and that any purchase made in the future will result in better performance. In contrary, it is assumed in our model that an asset of the same technological type will not improve automatically over time. Furthermore, the option of banking allowances is not considered in their model. 


\subsection{SUMMARY}

To Sum up, in addition to the fact that the literature appears to be extremely limited about parallel replacement problem under regulations of emissions trading systems, this work makes two main contributions to this part of the literature. First, it considers banking of emission allowances which is a natural characteristic of cap-and-trade by using a variable for banking of allowances in the model. This makes the model closer to real circumstances. Second, it contains a generic method to approach technological change while considering its environmental impacts. As it is discussed in detail in the next section, different technological types can be considered in the model, and it can be programmed that when each of these particular technologies will be available to use, or that which of the technologies can feasibly be transformed to which of the higher ones. This makes the model capable of many different scenarios for technological changes as opposed to some studies that consider a general trend of technological improvement over time, or a predefined and specific situation for technological advancement. 


\section{PROBLEM DESCRIPTION AND THE MODEL}

The goal of the model presented in this work is to help a firm to optimize its plan for utilization, replacement, and improvement of its fleet of assets, where the emissions are regulated by cap-andtrade. The firm that is being studied in this model owns multiple assets with different technological types and different ages, which results in different capacities for assets, and could impact the replacement decisions (Tanchoco and Leung 1987). In the introduction part, some examples of assets that can be studied in this parallel replacement model were mentioned e.g. lathes, computers, vehicles etc. The age of an asset in this model means the cumulative time an asset has been utilized and not the actual calendar age, since we assume that the assets do not deteriorate while they are in inventory and not being used. Each year, these assets must perform to satisfy a demand requirement (Hartman 2000). The firm has a limited budget for each year (Karabakal, Lohmann, and Bean 1994). At the beginning of each year, the firm has the option of taking one of the five following actions; first, it could purchase new assets from a variety of available technological types, and all newly purchased assets are assumed to be brand new. In other words, age equals zero for new purchases. The second option is improving existing assets to a higher technological type with two considerations; brand new assets cannot be improved, and not all improvements are possible. A three-dimension parameter is considered in the model that determines what improvements are possible at each year with one dimension being time and the two others being the initial and after-enhancement technological types. This consideration is capable of deeming an improvement that is not available for now but will be available in the future, which could be the case for many real-world problems. For example, it could be assumed that an improvement to the highest technological type is only feasible in the last 4 years of the time horizon. The third, fourth, 
and fifth options are putting the assets in use, putting them in inventory, and salvaging them.

Figure 3.1 visualizes the process of decision making at the beginning of each year. The arrow that shows the flow from the purchase and the flow to the salvage each have different patterns, since they indicate assets being added to the total assets in the system or assets being removed from the system. A dotted arrow indicates an asset being removed from the system, and a dashed arrow indicates a new asset is added to the system. Normal arrows indicate an asset moving within the system. Utilization and storage are highlighted and are different in shape owing to the fact that through the year an asset could only be in one of these two states. This means that if an asset goes to retrofit at the beginning of the year it cannot stay in that state through the year and must be utilized or stored once the enhancement is done.

Figure 3.1 The options ahead of an asset at the beginning of each year.

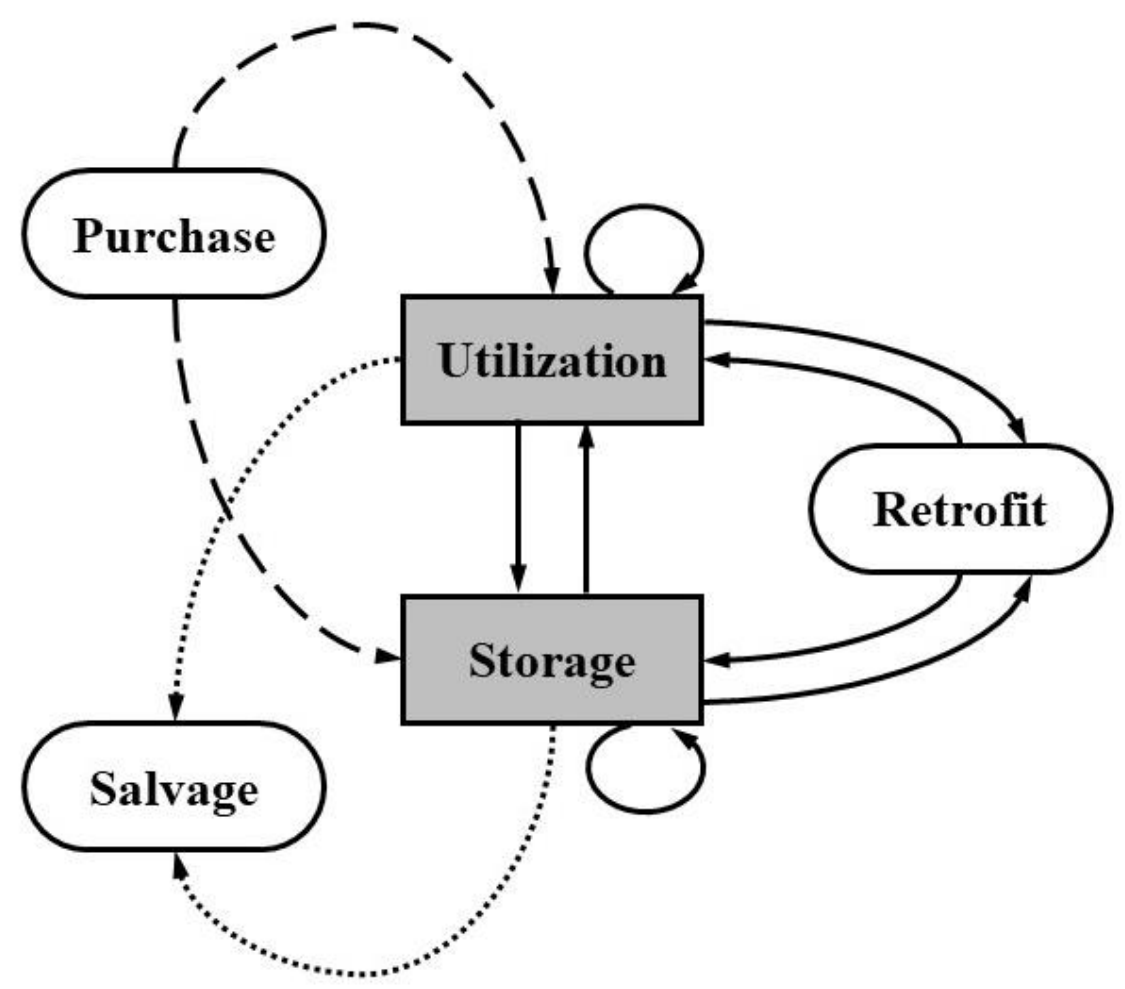


There are costs associated with each of those abovementioned options. For instance, operation and maintenance costs are associated with putting an asset in use, and inventory costs are associated with putting an asset in inventory. Also, improving existing assets or buying new ones will have their own costs. Alternatively, salvaging results in revenue for the firm. As we are studying the problem under regulations of cap-and-trade which puts a limit on emissions, although the management of the firm is probably interested in managing these costs and minimizing them, they might as well be concerned about the GHG emissions of its actions and decisions.

As explained earlier, the firm is in a jurisdiction where the emissions are regulated through a cap-and-trade market. There is a cap for the maximum GHGs the firm is allowed to emit. If the firm fails to reduce its emissions to a level below the cap then it should buy allowances in the emissions trading market, and in the case that it manages to reduce emissions to a level below the cap it can sell the extra allowances in the same market and earn some revenue. Therefore, in addition to the usual costs, the firm could be also concerned about the emissions related to each of the five abovementioned options. Hence, the objective of the problem is defined to be minimizing both the costs and GHG emissions while using the fleet of assets to meet the demand of each year.

The model is mixed integer with 7 sets of decision variables and 16 sets of constraints. The index $i$ indicates the period of time, and each period of time is considered to be a year. Index $j$ indicates the total utilization time or the age of an asset, and $k$ and $l$ indicate the technological type of an asset. Two indexes have been used for technological types, because variables that manage technological improvement work with two different technological types, before and after improvement.

The model is developed based on these assumptions: 
(1) There are $K$ technological types available.

(2) The model is planned for a time horizon of $T$ years.

(3) The maximum age allowed for any asset is $N$. This assumption and similar assumptions exist in the literature in many instances, and it is valid in most practical cases (J. C. Hartman \& Tan, 2014).

(4) The maximum age allowed for an asset to be improved is $M$.

(5) $M \leq N \leq T$.

(6) Only utilization time of an asset is meaningful in this model, e.g. if an asset is put to inventory, there will be no impact on its performance or operation and maintenance costs or its carbon footprint. In other words, assets stored in inventory do not deteriorate, so keeping track of their calendar age seems irrelevant.

(7) The actions of improvement and salvaging of an asset and the storing of an asset in inventory all take place at the beginning of each year.

(8) No improvement or purchase takes place in $i=0$, or the first year.

(9) All purchased assets are brand new $(j=0)$, and it is not allowed to improve an asset in the same year in which it was purchased.

(10) The firms could save emission permits, but they cannot owe them, which means if the firm does not use all its permits, it could save it for later. Nevertheless, if it has emitted more than the cap of the year, it should buy permits in the same year to meet the cap requirement. In other words, the value of the variable for saved permits cannot be negative.

(11) Downtimes were not considered in this work, which means any failure of an asset will be fixed in a short time and will not have any impacts on its capacity. 
Indices, variables, and parameters used in the model are shown in Table 3.1 with a brief description of each:

Table 3.1 Definition of indices, decision variables, and parameters.

\begin{tabular}{|c|c|}
\hline \multicolumn{2}{|l|}{ Indices } \\
\hline$i$ & Indicates the period of time or year \\
\hline$j$ & Indicates the utilization time of an asset \\
\hline$k$ & Indicates the technological type of an asset \\
\hline$l$ & $\begin{array}{l}\text { Indicates the technological type of an asset before or after an } \\
\text { improvement }\end{array}$ \\
\hline \multicolumn{2}{|c|}{ Decision Variables } \\
\hline$X_{i j k}$ & $\begin{array}{l}\text { Number of assets in operation in the year } i \text { with } j \text { years of utilization } \\
\text { belonging to technological type } k\end{array}$ \\
\hline$S_{i j k}$ & $\begin{array}{l}\text { Number of salvaged assets in the year } i \text { with } j \text { years of utilization } \\
\text { belonging to technological type } k\end{array}$ \\
\hline$Y_{i j k}$ & $\begin{array}{l}\text { Number of assets put to inventory in the year } i \text { with } j \text { years of utilization } \\
\text { belonging to technological type } k\end{array}$ \\
\hline$A_{i k}$ & $\begin{array}{l}\text { Number of purchased assets in the year } i \text { from technological type } k \text { (all } \\
\text { purchased assets are new) }\end{array}$ \\
\hline
\end{tabular}




\begin{tabular}{|c|c|}
\hline$Z_{i j k l}$ & $\begin{array}{l}\text { Number of assets that are improved to technological type } l \text { in the year } i \\
\text { with } j \text { years of utilization, which previously belonged to technological } \\
\text { type } k\end{array}$ \\
\hline$F_{i}$ & $\begin{array}{l}\text { Amount of emission permits saved as a result of reducing emissions or } \\
\text { trading in the year } i\end{array}$ \\
\hline$F T_{i}$ & $\begin{array}{l}\text { Amount of emission allowances/permits bought (or sold if its value is } \\
\text { negative) in the year } i\end{array}$ \\
\hline \multicolumn{2}{|c|}{ Economical Parameters } \\
\hline$c_{i j k}$ & $\begin{array}{l}\text { The production capacity of an asset in the year } i \text { with } j \text { years of utilization } \\
\text { belonging to technological type } k\end{array}$ \\
\hline$p_{i k}$ & The purchase cost of an asset in year $i$ belonging to technological type $k$ \\
\hline$e_{i j k l}$ & $\begin{array}{l}\text { Cost of improving of an asset to technological type } l \text { from technological } \\
\text { type } k \text { in the year } i \text { with } j \text { years of utilization }\end{array}$ \\
\hline$m_{i j k}$ & $\begin{array}{l}\text { Operation and maintenance costs of an asset in the year } i \text { with } j \text { years of } \\
\text { utilization belonging to technological type } k\end{array}$ \\
\hline$h_{i j k}$ & $\begin{array}{l}\text { Inventory cost of an asset in the year } i \text { with } j \text { years of utilization } \\
\text { belonging to technological type } k\end{array}$ \\
\hline$r_{i j k}$ & $\begin{array}{l}\text { The salvage value of an asset in the year } i \text { with } j \text { years of utilization } \\
\text { belonging to technological type } k\end{array}$ \\
\hline
\end{tabular}




\begin{tabular}{|c|c|}
\hline$n_{j k}$ & $\begin{array}{l}\text { Number of assets of technological type } k \text { with } j \text { years of utilization } \\
\text { available in the beginning of the time }\end{array}$ \\
\hline$d_{i}$ & Market demand in the year $i$ \\
\hline$p z_{i k l}$ & $\begin{array}{l}\text { The possibility of improving an asset from technological type } k \text { to } l \text { in the } \\
\text { year } i \text {. Its value is zero if such improvement is not feasible. }\end{array}$ \\
\hline \multicolumn{2}{|c|}{ Environmental Parameters } \\
\hline$q_{i k}$ & $\begin{array}{l}\text { Emissions associated with manufacturing, transporting, and installing an } \\
\text { asset or in other words environmental impacts of purchasing an asset of } \\
\text { technological type } k \text { in the year } i\end{array}$ \\
\hline$g_{i j k}$ & $\begin{array}{l}\text { Emissions associated with operating an asset of technological type } k \text { with } \\
j \text { years of utilization in the year } i\end{array}$ \\
\hline$w_{i j k}$ & $\begin{array}{l}\text { Emissions associated with keeping an asset of technological type } k \text { with } j \\
\text { years of utilization in the year } i \text { in inventory }\end{array}$ \\
\hline$v_{i j k}$ & $\begin{array}{l}\text { Emissions associated with salvaging an asset of technological type } k \text { with } \\
j \text { years of utilization in the year } i\end{array}$ \\
\hline$t_{i j k l}$ & $\begin{array}{l}\text { Emissions associated with improving an asset of technological type } k \text { to } \\
\text { type } l \text { with } j \text { years of utilization in the year } i\end{array}$ \\
\hline$f_{i}$ & Emissions cap in the year $i$ \\
\hline
\end{tabular}




\begin{tabular}{|c|l|}
\hline$F l$ & Maximum permits allowed to save \\
\hline$c v_{i}$ & Price of emission allowance in the year $i$ \\
\hline
\end{tabular}

The objective function of the model which is meant to minimize both ownership costs and GHG emissions is:

Minimize: $\quad \sum_{i} \sum_{k}\left(p_{i k}+q_{i k} * c v_{i}\right) A_{i k}$

$$
\begin{aligned}
& +\sum_{i} \sum_{j} \sum_{k}\left(m_{i j k}+g_{i j k} * c v_{i}\right) X_{i j k}+\left(h_{i j k}+w_{i j k} * c v_{i}\right) Y_{i j k} \\
& +\sum_{i} \sum_{j} \sum_{k} \sum_{l}\left(e_{i j k l}+t_{i j k l} * c v_{i}\right) Z_{i j k l}-\sum_{i} \sum_{j} \sum_{k}\left(r_{i j k}-v_{i j k} * c v_{i}\right) S_{i j k} \\
& +\sum_{i} F T_{i} * c v_{i}
\end{aligned}
$$

The objective function is subject to these constraints:

$$
\sum_{j} \sum_{k} c_{i j k} X_{i j k} \geq d_{i}, \forall i
$$

Constraint 3.1 shows that the production of each period should suffice for the demand of that year. Production is defined as the number of assets utilized multiplied by their respective capacities. 


$$
\begin{gathered}
X_{(i-1)(j-1) k}+Y_{(i-1) j k}-S_{(i-1) j k}-\sum_{l} Z_{(i-1) j k l}+\sum_{l} Z_{(i-1) j l k}=X_{i j k}+Y_{i j k}, \forall i>0, \\
j>0, k
\end{gathered}
$$

Constraint 3.2 is the flow of the assets from each year to the next. It explains what options are ahead of an asset each year. The options include being utilized, stored, improved, or salvaged. The summations indicate that all the improvement from a specific technological type or to that specific type should be considered.

$$
\begin{aligned}
\sum_{j} \sum_{k} g_{i j k} X_{i j k} & +w_{i j k} Y_{i j k}+v_{i j k} S_{i j k}+\sum_{k} q_{i k} A_{i k}+\sum_{k} \sum_{l} \sum_{j} Z_{i j k l} t_{i j k l} \\
= & f_{i}-\left(F_{i}-F_{i-1}\right)+F T_{i}, \forall i
\end{aligned}
$$

Constraint 3.3 relates to GHG emissions and the cap-and-trade market. It shows that the amount of emissions must be equal to the imposed cap of the year plus the use of saved permits and traded permits. As seen above, all the options that are on the table for the firm come at an environmental price.

$F_{i} \leq f l, \forall i$

Constraint 3.4 puts a limit on the maximum allowances that the firm could accumulatively bank.

$n_{j k}=X_{0 j k}+Y_{0 j k}+S_{0 j k}, \forall j, k$

Constraint 3.5 connects the parameter of assets in the first year with the three options available for assets in the first year. 
$A_{i k}=X_{i 0 k}+Y_{i 0 k}, \forall i, k$

Constraint 3.6 rules that all the new purchases of each year will be utilized or stored in the same year.

$A_{0 j k}=Z_{0 j k l}=0, \forall j, k, l$

Constraint 3.7 rules that based on the assumptions of the model, no purchases or improvements are allowed.

$S_{i 0 k}=0, \forall i, k$

Constraint 3.8 bans the salvage of brand-new or non-utilized assets.

$Z_{i j k l}, X_{i j k}, Y_{i j k}, S_{i j k}, A_{i j k} \in \mathbb{N}, \forall i, j, k, l$

Constraint 3.9 explains that all variables are integer except $F_{i}$ and $F T_{i}$. This is because all variables except $F_{i}$ and $F T_{i}$ represent numbers of assets, but $F_{i}$ and $F T_{i}$ are the variables for saving and trading the permits, respectively, which do not represent integer numbers.

$Z_{i j k l}, X_{i j k}, Y_{i j k}, S_{i j k}, A_{i j k}, F_{i} \geq 0, \forall i, j, k, l$

Constraint 3.10 makes all variables except $F T_{i}$ positive. $F T_{i}$ is the variable for trading emission allowances, and therefore, if obtains positive values it means in that year the firm should buy permits, and if obtains negative values it means that the firm should sell that amount of emission allowances.

$Z_{i j k l}=0, \forall j>M, i, k, l$ 
Constraint 3.11 explains that the maximum age for retrofit is $M$. Hence, if an asset has been utilized for more than $M$ years it cannot be improved.

$Z_{i j k l} \leq p z_{i k l} * \gamma, \forall i, j, k, l$

Constraint 3.12 indicates which transformations between two types of technology are possible. If the value is zero in parameter $p z_{i k l}$ - the matrix that determines which retrofit transformations are feasible - the associated decision variable of retrofit must also be zero. If the parameter's value is one, the decision variable could be either zero or any positive integer, so the model will determine the number of retrofit of that kind. Symbol $\gamma$ in the equation simply represents a very big number.

$X_{i N k}=Y_{i N k}=Z_{i N k l}=0, \forall i, k, l$

Constraint 3.13 demonstrates that the assets cannot be used, stored, or improve once they exceed their maximum age and must be salvaged.

$S_{T j k}=X_{T j k}+Y_{T j k} \forall j, k$

Constraint 3.14 indicates that all utilized assets and assets in inventory must be salvaged at the end of the time horizon.

$F_{0}=0$

Constraint 3.15 indicates that the firm has no emission permits banked in the first year.

$F T_{0} \geq 0$ 
Constraint 3.16 explains that the firm cannot sell any permits in the first year and shall either purchase permits or not trade at all.

Results of the model will inform the firm when to buy new assets, when to improve existing assets, whether to use an asset or to put in inventory in each year, and how to manage the permits and trade them in the market to meet the emission cap. 


\section{CASE STUDY, RESULTS, AND SENSITIVITY ANALYSIS}

\subsection{ORIGINAL RUN}

We used the data gathered by (Abdi, Taghipour, \& Khamooshi, 2018) [see Table 4.1] in our model with some modifications. The modifications entail adding another dimension to many of the parameters to consider different technological types, and in some cases tweaking the values slightly in order to make them compatible with our model's unique assumptions. The data used in this model is from a fleet of excavators in Ontario. The planning horizon of the model is considered 9 years. The maximum utilization allowed for an excavator is 6 years, and the maximum age of an excavator to be improvable is 4 years. Although the model is capable of deeming different technological improvement possibilities in different years, we presumed that any improvement to a higher technology is possible at all times. The functions that generate the data used in the model and other parameters followed by their values are listed in Table 4.1:

Table 4.1 Data generating functions.

\begin{tabular}{|c|c|c|}
\hline Parameter & Function used & unit \\
\hline$c_{i j k}$ & $85000-1000 j+5000 k$ & $\mathrm{~m}^{3}$ (cubic meter) \\
\hline$p_{i k}$ & $300000+10000 i+30000 k$ & $\$$ \\
\hline$e_{i j k l}$ & $20000(l-k)+1000 i+1000 j$ & $\$$ \\
\hline$m_{i j k}$ & $80000+500 i+1000 j-3000 k$ & $\$$ \\
\hline$h_{i j k}$ & & $\$$ \\
\hline
\end{tabular}




\begin{tabular}{|c|c|c|}
\hline$r_{i j k}$ & $180000-5000 j+1000 i+15000 k$ & $\$$ \\
\hline$d_{i}$ & $6500000+60000 i$ & $\mathrm{~m}^{3}$ \\
\hline$p z_{i k l}$ & $l$ if $l>k$, otherwise 0 & NA \\
\hline$q_{i k}$ & $1100-10 i+50 k$ & tons of $\mathrm{CO}_{2}-\mathrm{eq}$ \\
\hline$g_{i j k}$ & $500-50 i+50 j-85 k$ & tons of $\mathrm{CO}_{2}-\mathrm{eq}$ \\
\hline$w_{i j k}$ & $80-i+5 j-5 k$ & tons of $\mathrm{CO}_{2}-\mathrm{eq}$ \\
\hline$v_{i j k}$ & $120-i+5 j-7 k$ & tons of $\mathrm{CO}_{2}-\mathrm{eq}$ \\
\hline$t_{i j k l}$ & $400+100(l-k)-5 i+10 j$ & tons of $\mathrm{CO}_{2}-\mathrm{eq}$ \\
\hline$f_{i}$ & $7000-500 i$ & tons of $\mathrm{CO}_{2}-\mathrm{eq}$ \\
\hline$F l$ & 500,000 & tons of $\mathrm{CO}_{2}-\mathrm{eq}$ \\
\hline$c v_{i}$ & $15-0.3 i$ & $\$$ \\
\hline
\end{tabular}

It is assumed that there are four types of excavators available. The firm owns a total of 10 excavators of different types at the beginning of the time horizon. The number of excavators of each type that the firm possesses in $i=0$ is shown in Table 4.2:

Table 4.2 Assets owned by the firm in the first year.

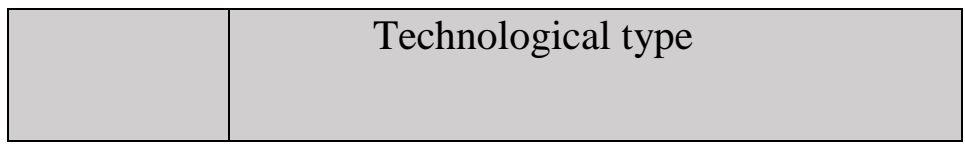




\begin{tabular}{|r|r|r|r|r|}
\hline age & 0 & 1 & 2 & 3 \\
\hline 0 & 0 & 0 & 0 & 0 \\
\hline 1 & 0 & 2 & 0 & 0 \\
\hline 2 & 0 & 4 & 0 & 0 \\
\hline 3 & 3 & 0 & 0 & 0 \\
\hline 4 & 0 & 1 & 0 & 0 \\
\hline 5 & & & & \\
\hline
\end{tabular}

We used (CPLEX, 2017) to solve this model on a personal computer running with the Windows 10 operating system, and a $3.20 \mathrm{GHz}$ CPU and 8.00 GB RAM.

The objective function's value is $\$ 8,397,599$. This is the minimum total cost that could be achieved by solving the model with the parameters provided in Table 4.1.

First, we discuss the variable of purchasing new assets. The model recommends purchasing from either the highest or the lowest technologies of excavators. As an example, the firm should buy 3 of the highest technological type and one of the lowest one in the second year. The model suggests that no purchases shall be made in the last 4 years. The list of all purchases can be found in Table 4.3: 
Table 4.3 New assets purchased.

\begin{tabular}{|c|c|c|c|c|}
\hline & \multicolumn{4}{|c|}{ Technological type } \\
\hline year & 0 & 1 & 2 & 3 \\
\hline 0 & 0 & 0 & 0 & 0 \\
\hline 1 & 1 & 0 & 0 & 3 \\
\hline 2 & 1 & 0 & 0 & 1 \\
\hline 3 & 3 & 0 & 0 & 0 \\
\hline 4 & 0 & 0 & 0 & 3 \\
\hline 5 & 0 & 0 & 0 & 0 \\
\hline 6 & 0 & 0 & 0 & 0 \\
\hline 7 & 0 & 0 & 0 & 0 \\
\hline 8 & 0 & 0 & 0 & 0 \\
\hline
\end{tabular}

Second, the variable of improvement is reviewed. Most of the improvements happen in the second year. There is one improvement in the third year and three improvements in the fourth year. The model does not urge any improvements after that. This could be explained by the fact that excavators with 5 years of utilization or more are not improvable. Table 4.4 shows all the improvements suggested by the model: 
Table 4.4 Improvement of assets.

\begin{tabular}{|r|r|r|r|r|}
\hline $\begin{array}{r}i \\
\text { (size 9) }\end{array}$ & (size 6) & (size 4) & (size 4) & Value \\
\hline 1 & 3 & 1 & 3 & 4 \\
\hline 3 & 1 & 0 & 3 & 3 \\
\hline 2 & 1 & 0 & 3 & 1 \\
\hline 1 & 2 & 1 & 3 & 1 \\
\hline 1 & 1 & 1 & 3 & 1 \\
\hline 1 & 1 & 0 & 3 & 1 \\
\hline
\end{tabular}

Both variables of purchasing and improvement seem to indicate that it is in the firm's interest to build up and adjust its fleet of excavators in the first half of the time horizon. Late purchases and improvements do not appear to be cost-efficient.

Third, the variable of saving or banking of allowances is examined. The model does not recommend keeping any emission allowances at all, which could be explained by the assumed decreasing trend in the carbon price. Therefore, the firm ought to buy only as much permits as it needs for the current year, and in case it did not use all the permits of one year, it should sell the extra permits the same year. 
Next, the variable of inventory is analyzed. The model keeps two of the excavators in inventory for the first year. In the second year, the number of excavators in inventory grows to 6, one of which is from the first year. In the third year, there are 4 excavators in inventory, but they are all different from the ones in the second year. The next three years after the third year, the variable of inventory shows 4 to 6 excavators in inventory. This number drops to only one excavator in the seventh year, and the model recommends no excavators in inventory after the seventh year.

The data shows that excavators do not remain in inventory for more than 3 years, and in most cases even less than that. The excavators are then either improved or utilized again. This could be justified by the limited time horizon of this case study. If an excavator is going to stay in inventory for more than one-third of the time horizon, it will probably be salvaged or improved. Table 4.5 shows the data on inventory:

Table 4.5 Assets put in inventory.

\begin{tabular}{|r|r|r|r|}
\hline \multicolumn{1}{r|}{$\begin{array}{r}\text { (size 9) } \\
\text { (size 6) }\end{array}$} & (size 4) & Value \\
\hline 3 & 1 & 3 & 5 \\
\hline 5 & 2 & 3 & 4 \\
\hline 4 & 1 & 3 & 4 \\
\hline 1 & & & \\
\hline & & & \\
\hline
\end{tabular}




\begin{tabular}{|r|r|r|r|}
\hline 2 & 1 & 3 & 3 \\
\hline 6 & 3 & 3 & 1 \\
\hline 4 & 2 & 3 & 1 \\
\hline 3 & 2 & 3 & 1 \\
\hline 2 & 2 & 3 & 1 \\
\hline 1 & 2 & 1 & 1 \\
\hline 1 & 1 & 1 & 1 \\
\hline 0 & 4 & 1 & 1 \\
\hline 0 & 1 & 1 & 1 \\
\hline & & & \\
\hline
\end{tabular}

Finally, the variable for salvaging excavators has the value of 4 , both in the second and fourth year, and 2 in the sixth year, and finally recommends salvaging all the remaining excavators at the end of the time horizon. The model shows a trend of more adjustments to the fleet in the beginning. The more it gets closer to the end of time horizon, the less becomes the tendency of the model to change the set of excavators. It suggests a balanced dedication of budget among purchasing new and improving the existing excavators. At this point, the question would be how much of these results depends on the values that are given to the parameters of the model. To examine that, a sensitivity analysis is conducted and studied in the next section. 


\subsection{SENSITIVITY ANALYSIS}

After discussing the solution of the model in the previous section, the different results that the model produces based on the change in the input data will be examined. The first analyzed parameter is the price of carbon in the market. If the decreasing pattern changes to a fixed cost of \$15 CAD for the entire duration of the time horizon, no significant change occurs, but the objective function obtains a value of $\$ 8,412,200 \mathrm{CAD}$, which is slightly higher than the original run. Should the carbon price's pattern change to an increasing pattern with the same slope instead of decreasing, the model recommends purchasing allowances as much as the regulation's limit allows. However, none of the other decision variables acquire different values in this scenario, and the objective function slightly increases to $\$ 8,416,220 \mathrm{CAD}$.

Should the slope of the increase in demand rise and the demand increases $80,000 \mathrm{~m}^{3}$ per year instead of $60,000 \mathrm{~m}^{3}$, the objective function changes to $\$ 9,369,949 \mathrm{CAD}$, and all the decision variables show a larger scale. This means more purchases, more improvements, and possession of more excavators throughout the time horizon. These results are not far from what would be expected from a higher growth rate in demand.

In contrary, if the annual growth of demand is lower and is at $40,000 \mathrm{~m}^{3}$ per year, the number of purchases and the number of excavators possessed decreases, yet a slight increase is observed in the variable of improvements. Moreover, the objective function drops to $\$ 7,476,591$ CAD.

If the base cost of improving excavators to a higher technology (i.e. the costs that do not change over time and are not dependent on the age of an excavator) is cut in half, the variable of 
improvement increases drastically. Furthermore, the model urges the firm to only buy excavators of the lowest technology in this case. Table 4.6 and Table 4.7 show the variables of purchasing and improvement respectively:

Table 4.6 The new assets purchased when the base cost of the improvement is cut in half.

\begin{tabular}{|c|c|c|c|c|}
\hline & & & & \\
\hline year & 0 & 1 & 2 & 3 \\
\hline 1 & 0 & 0 & 0 & 0 \\
\hline 2 & 8 & 0 & 0 & 0 \\
\hline 3 & 0 & 0 & 0 & 0 \\
\hline 4 & 3 & 0 & 0 & 0 \\
\hline 5 & 0 & 0 & 0 & 0 \\
\hline 6 & 2 & 0 & 0 & 0 \\
\hline 7 & 0 & 0 & 0 & 0 \\
\hline 8 & 0 & 0 & 0 & 0 \\
\hline 9 & 0 & 0 & 0 & 0 \\
\hline
\end{tabular}


Table 4.7 The assets improved when the base cost of the improvement is cut in half.

\begin{tabular}{|r|r|r|r|r|}
\hline $\begin{array}{r}i \\
\text { (size 9) }\end{array}$ & $\begin{array}{r}k \\
\text { (size 6) }\end{array}$ & (size 4) & (size 4) & \\
\hline 1 & 1 & 0 & 3 & 8 \\
\hline 1 & 3 & 1 & 3 & 4 \\
\hline 3 & 1 & 0 & 3 & 3 \\
\hline 5 & 1 & 0 & 3 & 2 \\
\hline 1 & 2 & 1 & 3 & 1 \\
\hline 1 & 1 & 1 & 3 & 1 \\
\hline
\end{tabular}

Not surprisingly, if the base cost of improvement increases, the model tends to suggest buying more advanced excavators and has less desire to improve existing ones. A $20 \%$ increase in the base cost would make the model suggest buying 3 excavators of the lowest kind and 9 of the most advanced type, and the total number of suggested improvements declines to 8 . If the base cost increases by $30 \%$ the total number of improvements drops to 2 , and if it increases by $37 \%$, the model recommends no improvement of any kind and suggests purchasing a total of 12 excavators, all of which shall be from the most advanced technological type. It can be concluded that the cost of improvement has a tremendous impact on the optimal decision of the firm. 
Therefore, an accurate assessment of the financial costs of improving assets is vital to plan the optimal strategy.

The change in the base price of purchasing excavators does not change any of the decision variables, and it only increases the objective function value. In contrary to this, a $2.5 \%$ increase in the price gap between the purchasing price of a technological type and the next technological type could lead to a substantial change in the decision variables. This would suggest that the firm should only buy 2 of the most advanced excavators in the second year, but the rest of its purchases ought to be from the most basic excavators. In this case, the number of improvements would also grow considerably. Table 4.8 and Table 4.9 show the data of the purchases and improvements' decision variables respectively:

Table 4.8 The new assets purchased with a $2.5 \%$ increase in the price gap between technological types.

\begin{tabular}{|c|c|c|c|c|}
\hline & \multicolumn{4}{|c|}{ Technological type } \\
\hline year & 0 & 1 & 2 & 3 \\
\hline 0 & 0 & 0 & 0 & 0 \\
\hline 1 & 6 & 0 & 0 & 2 \\
\hline 2 & 0 & 0 & 0 & 0 \\
\hline 3 & 3 & 0 & 0 & 0 \\
\hline 4 & 0 & 0 & 0 & 0 \\
\hline
\end{tabular}




\begin{tabular}{|r|r|r|r|r|}
\hline 5 & 2 & 0 & 0 & 0 \\
\hline 6 & 0 & 0 & 0 & 0 \\
\hline 7 & 0 & 0 & 0 & 0 \\
\hline 8 & 0 & 0 & 0 & 0 \\
\hline
\end{tabular}

Table 4.9 The assets purchased with $2.5 \%$ increase in price gap between technological types

\begin{tabular}{|r|r|r|r|r|}
\hline $\begin{array}{r}i \\
\text { (size 9) }\end{array}$ & $\begin{array}{r}j \\
(\text { size } 6)\end{array}$ & (size 4) & (size 4) & \\
\hline 1 & 1 & 0 & 3 & 6 \\
\hline 1 & 3 & 1 & 3 & 4 \\
\hline 3 & 1 & 0 & 3 & 3 \\
\hline 5 & 1 & 0 & 3 & 2 \\
\hline 1 & 2 & 1 & 3 & 1 \\
\hline 1 & 1 & 1 & 3 & 1 \\
\hline
\end{tabular}

Based on these results, it is understood that the gap between the prices of technological types could change the solution of the model significantly. The prices of technologically assorted excavators, and the costs associated with improving them, would be expected to have a key role in the results of the model's solution. Gathering accurate data is one of the most important tasks 
that the firm must perform, if not the most important. As observed for some parts of the data, even one percent alteration could make an influential difference in the solution of the model.

Table 4.10 summarizes the results of sensitivity analysis experiments conducted in four categories.

Table 4.10 Sensitivity analysis summary

\begin{tabular}{|l|l|}
\hline Parameter & Sensitivity \\
\hline Carbon price & Medium \\
\hline Demand & Medium \\
\hline Retrofit cost & Very high \\
\hline Purchasing base cost & Low \\
\hline Purchasing cost gap between types & High \\
\hline
\end{tabular}




\section{CONCLUSION AND FUTURE RECOMMENDATIONS}

\subsection{CONCLUSION}

Compared to other methods of confronting the problem of global climate change, emissions trading systems are rather newer. Hence, the literature seems to be open to a lot of new works. Still, a lot of studies could be done in the field of optimization and OR modelling under cap-andtrade regulated markets, especially regarding parallel asset management. It is believed that capand-trade systems are yet to be implemented widely in the developed countries and that the future of mitigation of carbon and other GHG emissions will be more inclined to the use of emissions trading systems.

As cap-and-trade regulations become more common, the classic models for problems like parallel asset management and their solutions are to become less practical and the literature will feel the thirst for new works that consider new environmental regulations and factors in them.

In this thesis, first, the literature around the carbon pricing instruments was reviewed. Then the literature around the replacement problem and parallel asset management was contemplated, and finally, the works around models considering the environmental factors were introduced. Next, the problem of this thesis was described in details and the model was presented comprehensively. The thesis then continued to go through the results of the model and their interpretation, and finally, a complete sensitivity analysis was conducted. 


\subsection{RECOMMENDATIONS}

The use of this mathematical model could help companies reduce their costs and GHG emissions significantly. Considering the seven decision variables in our model, its solutions suggest detailed answers to the decision-makers of the firm. The flexibility of this model gives it the potential to be used by a broad variety of businesses and under different circumstances or different scenarios. Moreover, compared to previous models proposed in the literature of replacement problem and parallel asset management, this work takes new aspects of the problem into consideration and makes it closer to the lifelike complexity of the problem.

Different available technologies for assets were deemed and it was made possible to consider a future technology to become available somewhere in the planning horizon of our model. This means that if a company knows when newer technology will become available, or when an existing technology will be extinct, they can use our model to take that into consideration. Finally, adding a banking feature of the cap-and-trade market in this model is another novelty of this work. Solutions of our model could help a firm decide how to manage their emission allowances to gain more financial profit while reducing their emissions. Provided that a firm has an accurate estimation of the future of carbon price, this model gives a detailed action plan regarding emissions permit management.

As both the results of the original run and the runs associated with the analysis of sensitivity expressed, the accurate and precise collection of data and information used to feed the model is a very critical factor. In order to obtain meaningful and correct results from the model, it is important to use accurate parameters. Especially, the firms must do as best as they could in finding the costs 
associated with a retrofit, as even slight changes in the base cost or the increments of the cost of improvement or retrofit can have a huge impact on the results of the model.

\subsection{LIMITATIONS AND FUTURE WORK}

There are yet some improvements that could be made to make this work more accurate. Firstly, this work deems deterministic parameters in the model, but as the nature of the pricing in markets like cap-and-trade is stochastic, it could be very valuable to consider the uncertainty of the problem.

Secondly, no downtimes were considered in this work. This means that any failure of an asset will be fixed in a short time, and therefore, it will not have any impacts on its capacity. Reliability of the assets can be another aspect of the model that is open to expansion. To make the model closer to reality, stochastic methods could be also used to predict the time of occurrence and durations of such breaks.

Finally, more detailed consideration of scope 1, 2, 3 GHG emissions could be an important opportunity for future work. Although we tried to expand the scope of emissions and consider most of the indirect emissions caused by the management of a fleet of assets in our work, in the future there could be a clear classification of emissions considered as it supposedly will be the concern of future GHG control regulations. 


\section{APPENDIX: CPLEX MIXED INTEGER PROGRAM SOURCE CODE}

The code presented in this section exactly represents the model from Chapter 3. The data generating functions were coded using the "execute" statement in CPLEX programming language. Should businesses want to change the input data, they may do so by either using the "execute" statement or adding the data directly to the database using CPLEX itself.

Indices, decision variables, economic parameters, and environmental parameters are specified using the comments within the code. Constraints are also numbered for the ease of recognition. 


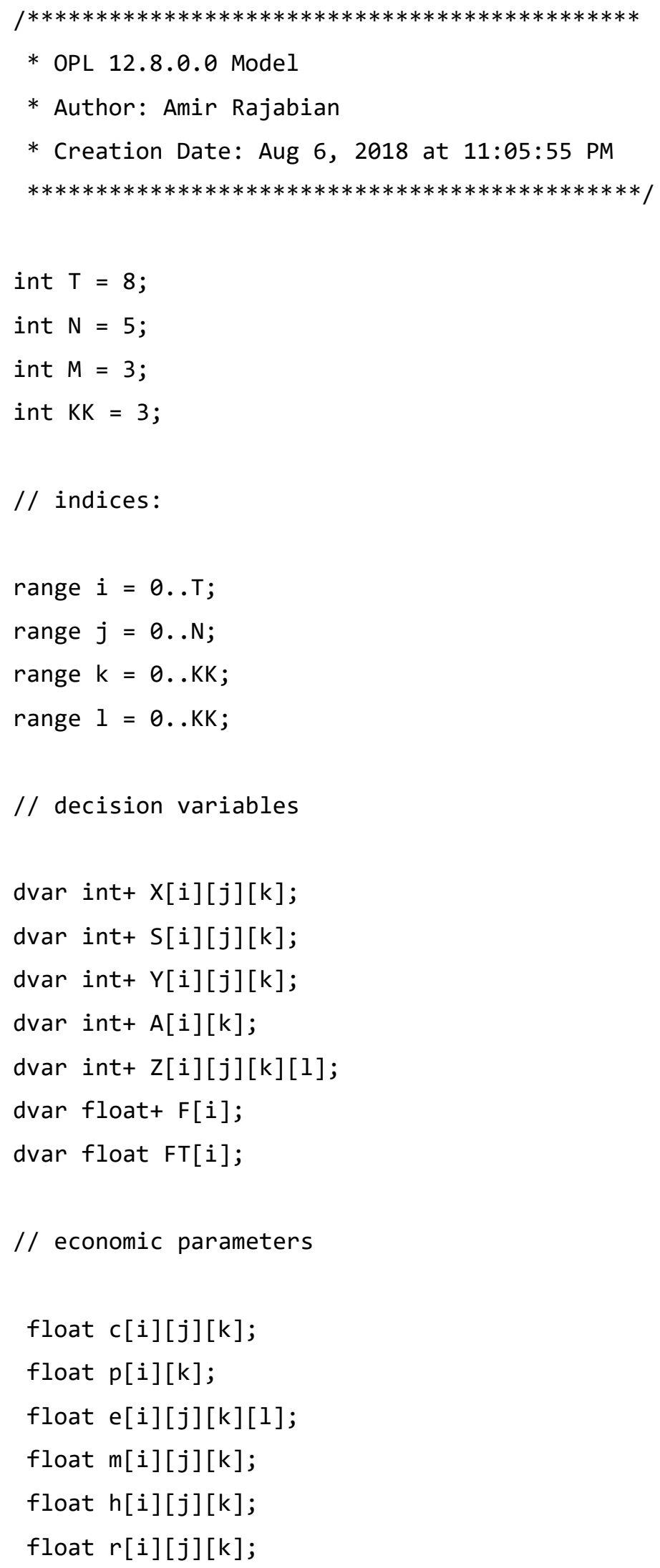




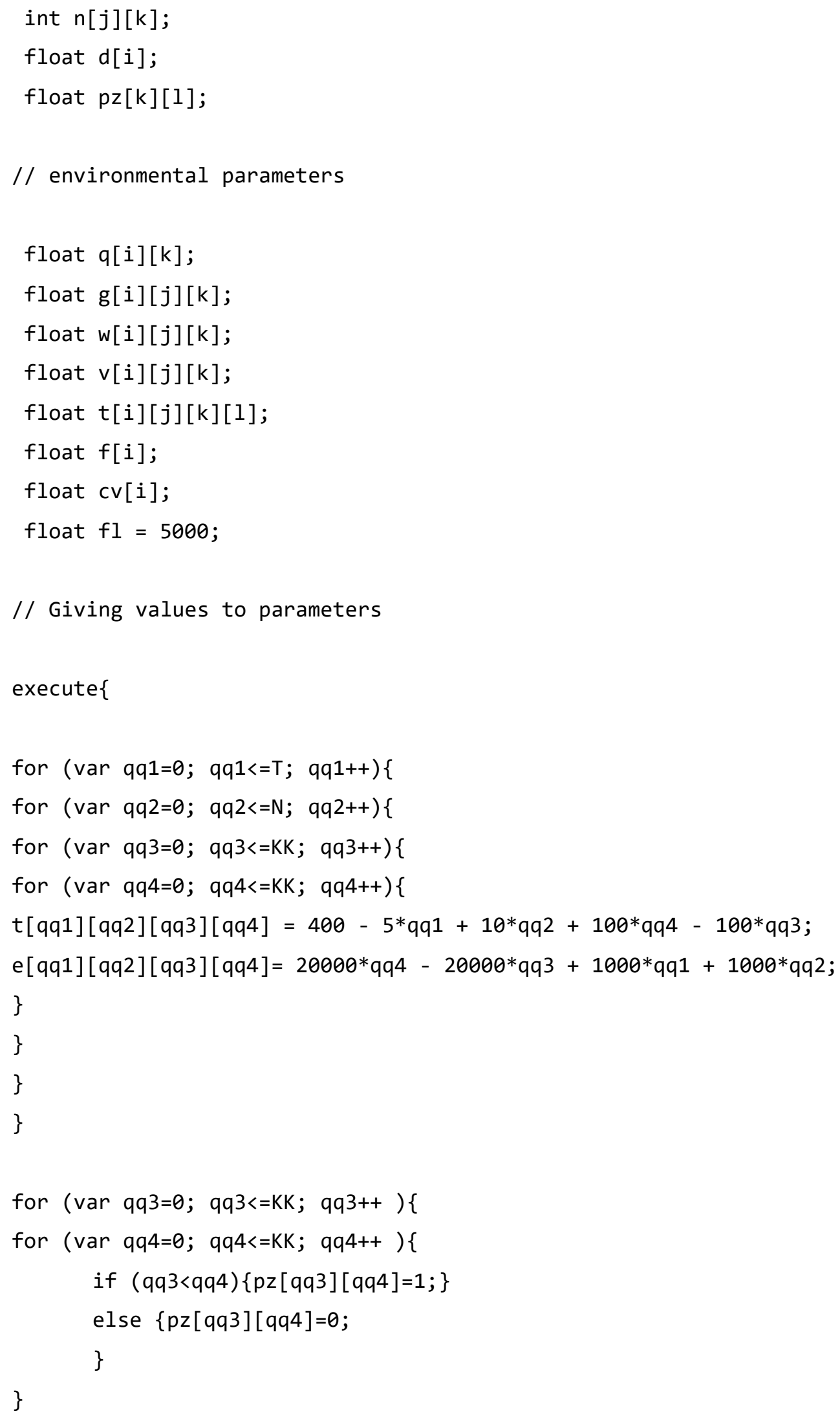




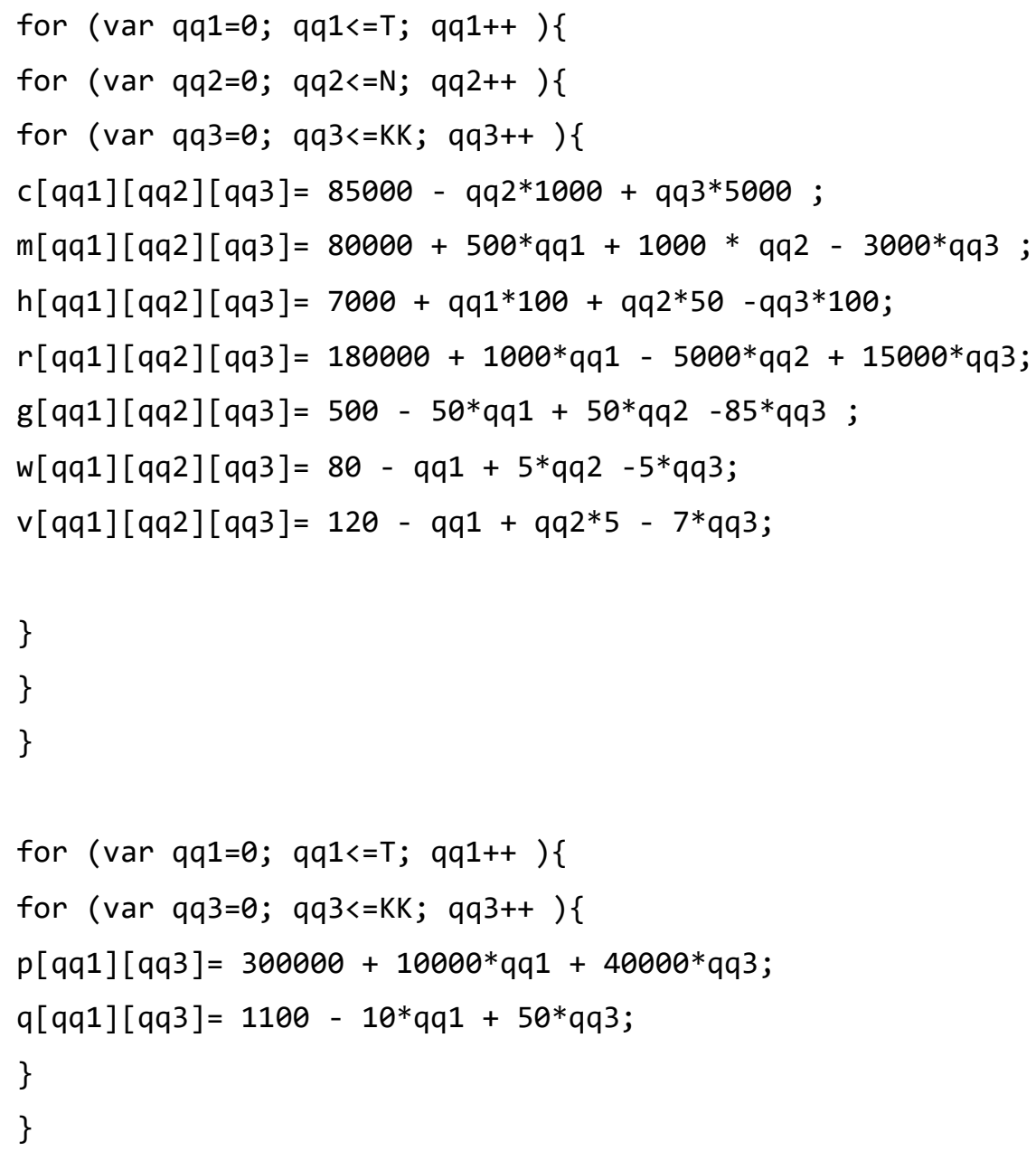




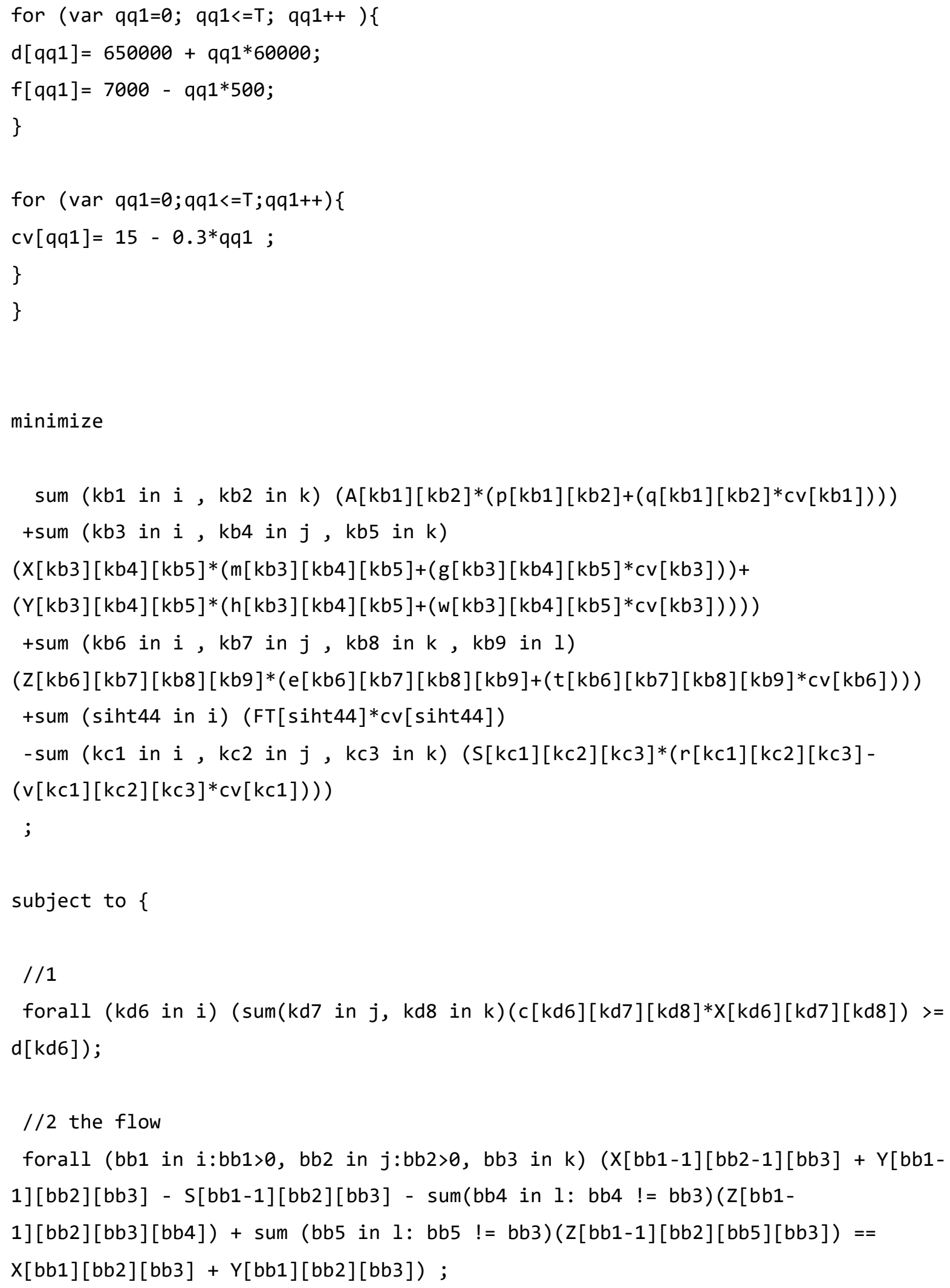




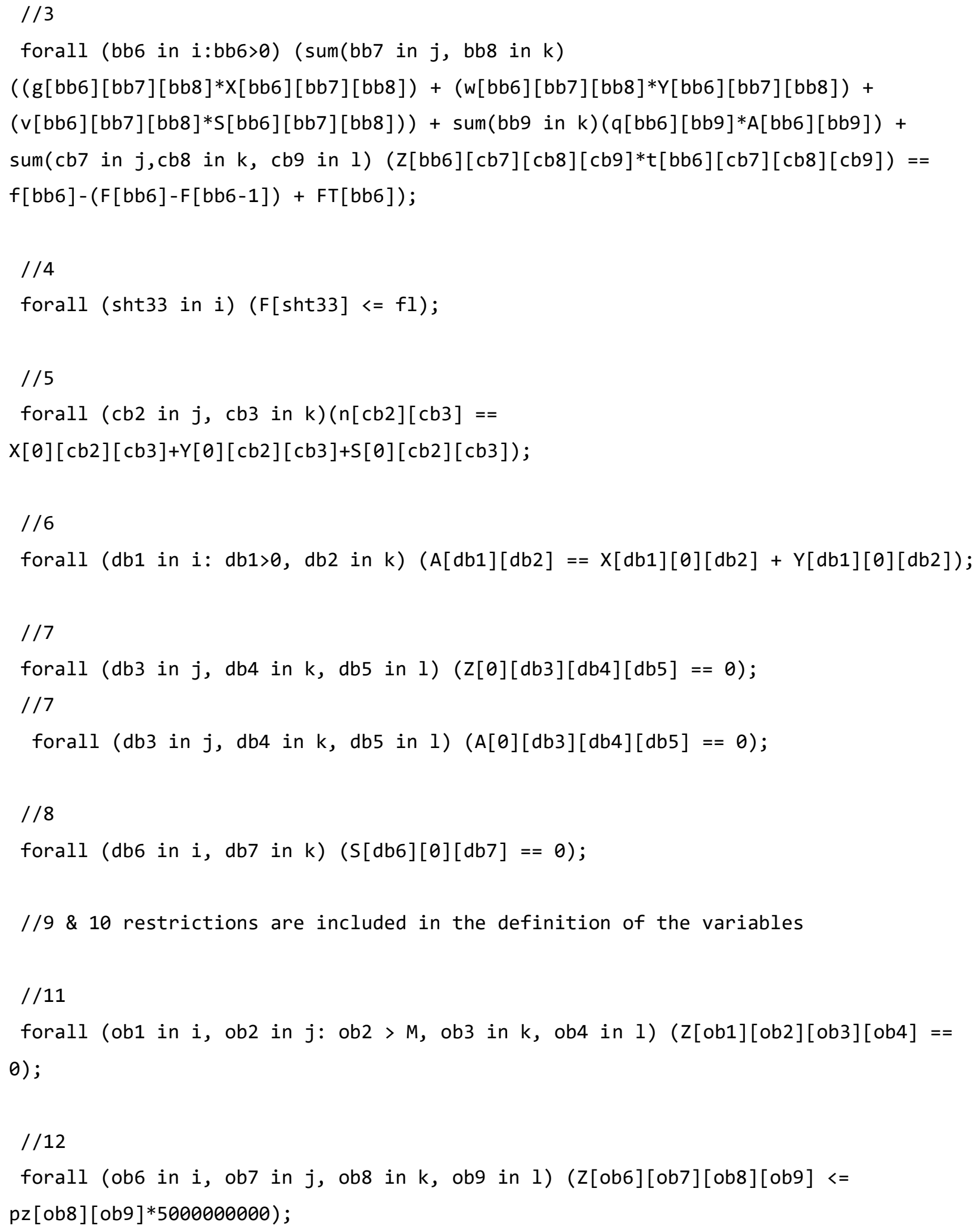




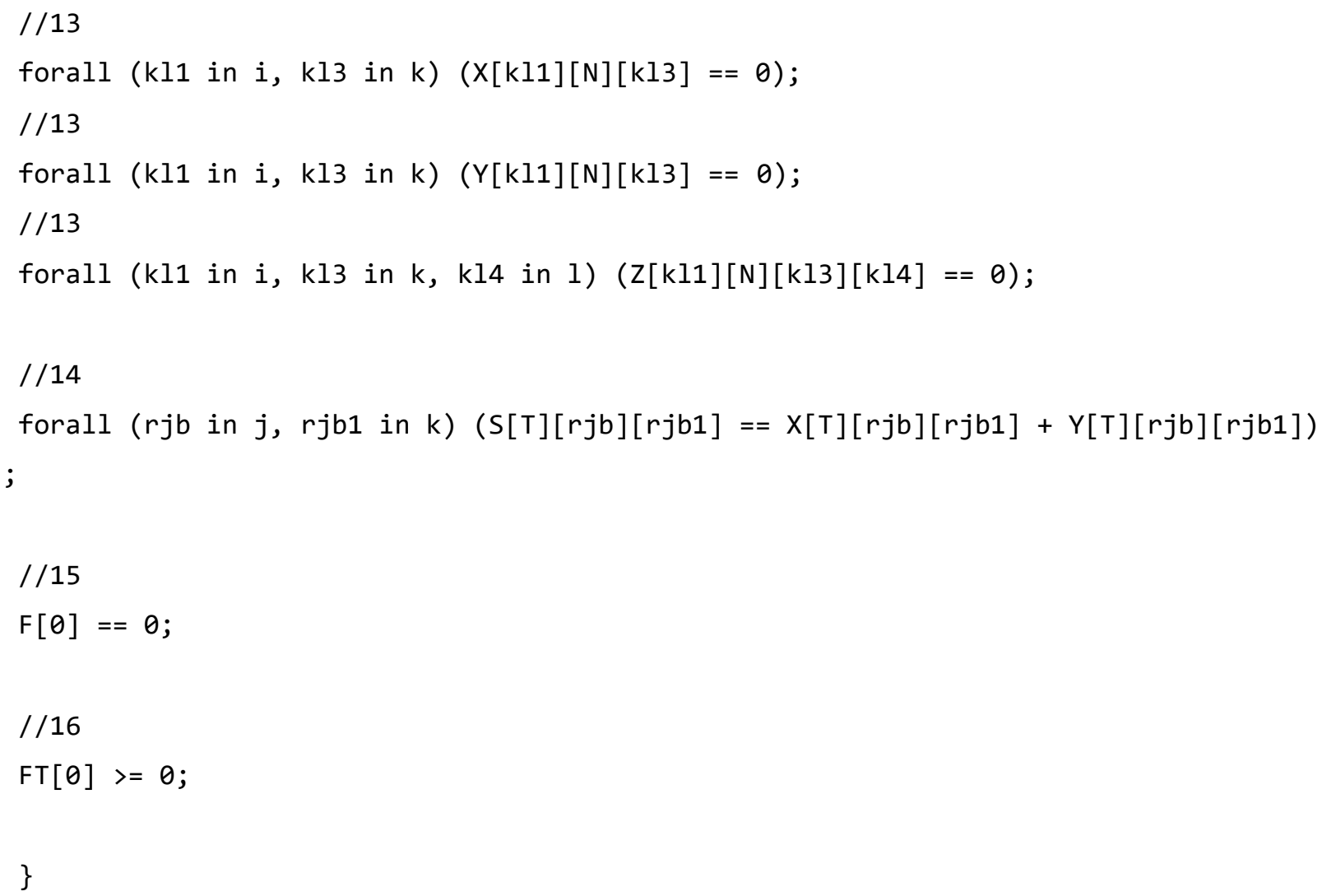




\section{REFERENCES}

1. Abdi, A., \& Taghipour, S. (2018). An optimization model for fleet management with economic and environmental considerations, under a cap-and-trade market. Journal of cleaner production, 204, 130-143.

2. Abdi, A., Taghipour, S., \& Khamooshi, H. (2018). A model to control environmental performance of project execution process based on greenhouse gas emissions using earned value management. International Journal of Project Management, 36(3), $397-$ 413.

3. Afrinaldi, F., Tasman, A. M., Zhang, H.-C., \& Hasan, A. (2017). Minimizing economic and environmental impacts through an optimal preventive replacement schedule: Model and application. Journal of cleaner production, 143, 882-893.

4. Ahani, P., Arantes, A., \& Melo, S. (2016). A portfolio approach for optimal fleet replacement toward sustainable urban freight transportation. Transportation Research Part D: Transport and Environment, 48, 357-368.

5. Aulisi, A., Farrell, A. E., Pershing, J., \& VanDeveer, S. (2005). Greenhouse gas emissions trading in US states: Observations and lessons from the OTC NOx budget program. United States Retrieved from https://www.osti.gov/biblio/20712286

6. A Brief Look At The Quebec Cap-And-Trade-System For Emission Allowances. (2018). Government of Quebec

7. Building a low-carbon economy-the UK's contribution to tackling climate change. (2008). Climate Change Committee 
8. Büyüktahtakın, İ. E., \& Hartman, J. C. (2016). A mixed-integer programming approach to the parallel replacement problem under technological change. International Journal of Production Research, 54(3), 680-695.

9. Büyüktahtakın, İ. E., Smith, J. C., Hartman, J. C., \& Luo, S. (2014). Parallel asset replacement problem under economies of scale with multiple challengers. The Engineering Economist, 59(4), 237-258.

10. Canadian Environmental Sustainability Indicators: Greenhouse gas emissions. (2018). Environment and Climate Change Canada Retrieved from https://www.canada.ca/en/environment-climate-change/services/environmentalindicators/greenhouse-gas-emissions.html

11. The cap and trade program. (2016). Government of Ontario

12. Christer, A., \& Scarf, P. (1994). A robust replacement model with applications to medical equipment. Journal of the Operational Research Society, 45(3), 261-275.

13. CPLEX. (2017). IBM ILOG CPLEX Optimization Studio (Version 12.8.0.0). Retrieved from https://www.ibm.com/ca-en/marketplace/ibm-ilog-cplex

14. de Macedo, P. P., de Miranda Mota, C. M., \& Sola, A. V. H. (2018). Meeting the Brazilian Energy Efficiency Law: A flexible and interactive multicriteria proposal to replace non-efficient motors. Sustainable Cities Society, 41, 822-832.

15. Derman, C. (1963). On optimal replacement rules when changes of state are Markovian. Mathematical optimization techniques, 396, 201-210.

16. Dow Corning Silicone Pumps. (2019). Retrieved from https://h-g.com/dow-corningsilicone-pumps/ Accessed April 2019 
17. Ellerman, A. D., Joskow, P. L., Schmalensee, R., Bailey, E. M., \& Montero, J.-P. (2000). Markets for clean air: The US acid rain program: Cambridge University Press.

18. Fan, W., Machemehl, R. B., \& Kortum, K. (2011). Equipment Replacement Optimization: Solution Methodology, Statistical Data Analysis, and Cost Forecasting. Transportation Research Record, 2220(1), 88-98.

19. Farrell, A., Carter, R., \& Raufer, R. (1999). The NOx Budget: market-based control of tropospheric ozone in the northeastern United States. Resource Energy Economics, 21(2), 103-124.

20. Feldman, R. M., \& Valdez-Flores, C. (2014). Applied probability and stochastic processes: Springer Science \& Business Media.

21. Feng, W., \& Figliozzi, M. (2013). An economic and technological analysis of the key factors affecting the competitiveness of electric commercial vehicles: A case study from the USA market. Transportation Research Part C: Emerging Technologies, 26, 135-145.

22. Former coal-fired power plant in Ontario becomes solar facility. (2019, April 1). Mining.com. Retrieved from http://www.mining.com/former-coal-fired-power-plantontario-becomes-solar-facility/

23. Fraser, J. M., \& Posey, J. W. (1989). A framework for replacement analysis. European Journal of Operational Research, 40(1), 43-57.

24. Hartman, J., \& Ban, J. (2002). The series-parallel replacement problem. Robotics and Computer-Integrated Manufacturing, 18(3-4), 215-221.

25. Hartman, J. C., \& Tan, C. H. (2014). Equipment replacement analysis: a literature review and directions for future research. The Engineering Economist, 59(2), 136-153.

26. Hastings, N. A. (2010). Physical asset management (Vol. 2): Springer. 
27. Hatoyama, Y. (1984). On Markov maintenance problems. IEEE transactions on reliability, 33(4), 280-283.

28. He, H., Fan, J., Li, Y., \& Li, J. (2017). When to switch to a hybrid electric vehicle: A replacement optimisation decision. Journal of cleaner production, 148, 295-303.

29. Hoeller, P., \& Wallin, M. (1991). OECD Economic Studies No. 17, Autumn 1991. Energy Prices, Taxes and Carbon Dioxide Emissions. Organisation for Economic Cooperation and Development, 92.

30. Implementing Canada's plan to address climate change and grow the economy: Putting a price on carbon pollution. (2018). Environment and Climate Change Canada Retrieved from https://www.canada.ca/content/dam/eccc/documents/pdf/climate-change/pricingpollution/ECCC_Technical_Deck_En.pdf

31. Imre, J. In: Pexels.

32. Jardine, A. K., \& Tsang, A. H. (2013). Maintenance, Replacement, and Reliability: Theory and Applications: CRC Press.

33. Kossoy, A. (2015). State and trends of carbon pricing: World Bank Publications.

34. Mardin, F., \& Arai, T. (2012). Capital equipment replacement under technological change. The Engineering Economist, 57(2), 119-129.

35. Meyer, B. C. (1993). Market obsolescence and strategic replacement models. The Engineering Economist, 38(3), 209-221.

36. Ngo, H. H., Shah, R., \& Mishra, S. (2018). Optimal asset management strategies for mixed transit fleet. Transportation Research Part A: Policy Practice, 117, 103-116.

37. Purdon, M., Houle, D., \& Lachapelle, E. (2014). The Political Economy of California and Quebec's Cap-and-Trade Systems: Sustainable Prosperity (University of Ottawa). 
38. Regnier, E., Sharp, G., \& Tovey, C. (2004). Replacement under ongoing technological progress. IIE Transactions, 36(6), 497-508.

39. Rezwan, A., Pixabay, \& Skitterphoto. In: Pexels.

40. Riechi, J., Mácian, V., Tormos, B., \& Avila, C. (2017). Optimal fleet replacement: A case study on a Spanish urban transport fleet. Journal of the Operational Research Society, 68(8), 886-894.

41. Scarf, P., \& Hashem, M. (2002). Characterization of optimal policy for capital replacement models. IMA Journal of Management Mathematics, 13(4), 261-271.

42. Scarf, P. A., \& Hashem, M. H. (1997). On the application of an economic life model with a fixed planning horizon. International Transactions in Operational Research, 4(2), 139150.

43. Skjærseth, J. B., \& Wettestad, J. (2016). EU emissions trading: initiation, decisionmaking and implementation: Routledge.

44. Stavins, R. N. (2003). Experience with market-based environmental policy instruments. In Handbook of environmental economics (Vol. 1, pp. 355-435): Elsevier.

45. Stocker, T. (2014). Climate change 2013: the physical science basis: Working Group I contribution to the Fifth assessment report of the Intergovernmental Panel on Climate Change: Cambridge University Press.

46. Sydbom, A., Blomberg, A., Parnia, S., Stenfors, N., Sandström, T., \& Dahlen, S. (2001). Health effects of diesel exhaust emissions. European Respiratory Journal, 17(4), 733746.

47. Taylor, J. S. (1923). A statistical theory of depreciation: Based on unit cost. Journal of the American Statistical Association, 18(144), 1010-1023. 
48. Terborgh, G. W. (1949). Dynamic equipment policy.

49. Turin, D. R. (2012). The Challenges of Climate Change Policy: Explaining the Failure of Cap and Trade in the United States With a Multiple-Streams Framework. Inquiries Journal, 4(06).

50. United Nations Framework Convention on Climate Change. (1992). In: United Nations.

51. United Nations framework convention on climate change. (1997). In Kyoto Protocol: United Nations.

52. United nations framework convention on climate change. (2015). In Paris Agreement: United Nations.

53. Vander Veen, D. J., \& Jordan, W. C. (1989). Analyzing trade-offs between machine investment and utilization. Management Science, 35(10), 1215-1226.

54. Verheyen, P. (1979). Economic interpretation of models for the replacement of machines. European Journal of Operational Research, 3(2), 150-156.

55. Wang, K.-J., \& Nguyen, P. H. (2017). Capacity planning with technology replacement by stochastic dynamic programming. European Journal of Operational Research, 260(2), 739-750.

56. Wittneben, B. B. (2009). Exxon is right: Let us re-examine our choice for a cap-and-trade system over a carbon tax. Energy Policy, 37(6), 2462-2464.

57. Yatsenko, Y., \& Hritonenko, N. (2011). Economic life replacement under improving technology. International Journal of Production Economics, 133(2), 596-602.

58. Yatsenko, Y., \& Hritonenko, N. (2017a). Machine replacement under evolving deterministic and stochastic costs. International Journal of Production Economics, 193, 491-501. 
59. Yatsenko, Y., \& Hritonenko, N. (2017b). Two-cycle optimization in replacement models with non-exponential technological improvement. IMA Journal of Management Mathematics, 28(3), 359-372.

60. Yuan, M., Zhang, Q., Wang, B., Liang, Y., \& Zhang, H. (2019). A mixed integer linear programming model for optimal planning of bicycle sharing systems: A case study in Beijing. Sustainable Cities Society, 101515.

61. Zhang, Y.-J., \& Wei, Y.-M. (2010). An overview of current research on EU ETS:

Evidence from its operating mechanism and economic effect. Applied Energy, 87(6), 1804-1814.

62. Zheng, S., \& Chen, S. (2018). Fleet replacement decisions under demand and fuel price uncertainties. Transportation Research Part D: Transport Environment, 60, 153-173. 